\title{
Consistency of aerosols above clouds characterization from A-Train active and passive measurements
}

\author{
Lucia T. Deaconu ${ }^{1}$, Fabien Waquet ${ }^{1}$, Damien Josset ${ }^{2}$, Nicolas Ferlay ${ }^{1}$, Fanny Peers $^{3}$, François Thieuleux ${ }^{1}$, \\ Fabrice Ducos ${ }^{1}$, Nicolas Pascal ${ }^{4}$, Didier Tanré ${ }^{1}$, Jacques Pelon ${ }^{5}$, and Philippe Goloub ${ }^{1}$ \\ ${ }^{1}$ Université de Lille, CNRS, UMR 8518, LOA - Laboratoire d'Optique Atmosphérique, 59000 Lille, France \\ ${ }^{2}$ US Naval Research Laboratory, NASA Stennis Space Center, 39529, Mississippi, USA \\ ${ }^{3}$ College of Engineering, Mathematics and Physical Sciences, University of Exeter, Exeter, UK \\ ${ }^{4}$ ICARE Data and Services Center, University of Lille, Villeneuve d'Ascq, 59655, France \\ ${ }^{5}$ LATMOS, Université Paris, (CNRS-UVSQ), Paris 75005, France \\ Correspondence to: Lucia T. Deaconu (lucia-timea.deaconu@ed.univ-lille1.fr) \\ and Fabien Waquet (fabien.waquet@univ-lille1.fr)
}

Received: 10 February 2017 - Discussion started: 13 March 2017

Revised: 20 July 2017 - Accepted: 1 August 2017 - Published: 22 September 2017

\begin{abstract}
This study presents a comparison between the retrieval of optical properties of aerosol above clouds (AAC) from different techniques developed for the A-Train sensors CALIOP/CALIPSO and POLDER/PARASOL. The main objective is to analyse the consistency between the results derived from the active and the passive measurements. We compare the aerosol optical thickness (AOT) above optically thick clouds (cloud optical thickness (COT) larger than 3) and their Angström exponent (AE). These parameters are retrieved with the CALIOP operational method, the POLDER operational polarization method and the CALIOP-based depolarization ratio method (DRM) - for which we also propose a calibrated version (denominated DRM SODA is the Synergized Optical Depth of Aerosols). We analyse 6 months of data over three distinctive regions characterized by different types of aerosols and clouds. Additionally, for these regions, we select three case studies: a biomass-burning event over the South Atlantic Ocean, a Saharan dust case over the North Atlantic Ocean and a Siberian biomass-burning event over the North Pacific Ocean. Four and a half years of data are studied over the entire globe for distinct situations where aerosol and cloud layers are in contact or vertically separated. Overall, the regional analysis shows a good correlation between the POLDER and the

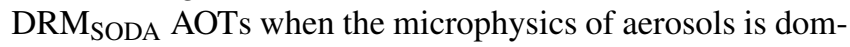
inated by fine-mode particles of biomass-burning aerosols from southern Africa (correlation coefficient $\left(R^{2}\right)$ of 0.83 ) or
\end{abstract}

coarse-mode aerosols of Saharan dust ( $R^{2}$ of 0.82$)$. A good correlation between these methods ( $R^{2}$ of 0.68 ) is also observed in the global treatment, when the aerosol and cloud layers are separated well. The analysis of detached layers also shows a mean difference in AOT of 0.07 at $532 \mathrm{~nm}$ between POLDER and DRM ${ }_{S O D A}$ at a global scale. The correlation between the retrievals decreases when a complex mixture of aerosols is expected $\left(R^{2}\right.$ of 0.37$)$ - as in the East Asia region - and when the aerosol-cloud layers are in contact $\left(R^{2}\right.$ of 0.36). The correlation coefficient between the CALIOP operational method and POLDER is found to be low, as the CALIOP method largely underestimates the aerosol loading above clouds by a factor that ranges from 2 to 4 .

Potential biases on the retrieved AOT as a function of cloud properties are also investigated. For different types of scenes, the retrieval of above-cloud AOT from POLDER and from DRM are compared for different underlying cloud properties (droplet effective radius $\left(r_{\text {eff }}\right)$ and COT retrieved with MODIS). The results reveal that DRM AOT vary with $r_{\text {eff }}$. When accounting for $r_{\text {eff }}$ in the DRM algorithm, the consistency between the methods increases. The sensitivity study shows that an additional polarized signal coming from aerosols located within the cloud could affect the polarization method, which leads to an overestimation of the AOT retrieved with POLDER algorithm. In addition, the aerosols attached to or within the cloud can potentially impact the DRM retrievals through the modification of the cloud droplet 
chemical composition and its ability to backscatter light. The next step of this work is to combine POLDER and CALIOP to investigate the impacts of aerosols on clouds and climate when these particles are transported above or within clouds.

\section{Introduction}

By interacting with radiations and by modifying the cloud reflectivity and microphysics, aerosols have important impacts on the Earth's radiative budget and water cycle (IPCC, 2013). These atmospheric particles absorb and scatter the sunlight, resulting in the so-called direct radiative effect (DRE). Although aerosols always produce a cooling effect at the Earth's surface, the sign and the amplitude of the DRE of aerosols at the top of the atmosphere depend not only on the aerosol properties but also on the reflective properties of underlying surface. For instance, in cases where absorbing aerosol layers are located above clouds, the DRE of aerosols is predominantly positive as a result of the reduction of the local planetary albedo (Keil and Haywood, 2003). By absorbing sunlight, aerosols also warm the layer of the atmosphere where they reside. This modifies the vertical profile of temperature in the atmosphere, which may affect the process of evaporation and cloud formation. This effect is called the semi-direct effect (Hansen et al., 1997; Ramanathan et al., 2001). Aerosols also impact the cloud properties by acting as cloud condensation nuclei and ice nuclei. They may modify the cloud microphysics and cloud brightness with potential impacts on precipitation and cloud lifetime (Rosenfeld, 2000; Twomey, 1974). These effects are referred as aerosol indirect effects and tend to cool the Earth.

The lack of knowledge of aerosol properties in cases of scenes of aerosols above clouds (AAC) has been recently highlighted as a source of uncertainty for the estimation of all-sky DRE of aerosols (Peers et al., 2016). Different approaches have been developed to quantify the DRE of AAC using satellite observations (Chand et al., 2009; Feng and Christopher, 2015; Meyer et al., 2013). But despite recent observational and modelling studies (De Graaf et al., 2014; Peers et al., 2015, 2016; Zhang et al., 2016), the aerosol DRE for AAC remains a subject of large uncertainty. In the process of quantification and interpretation of the aerosol impact on climate, the aerosol interactions with clouds constitute the largest uncertainty in global climate models (Myhre et al., 2013a, b). The study of AAC may also contribute to reduce those uncertainties. For instance, in case of absorbing AAC, the warming of the atmosphere occurring above stratocumulus clouds might reduce the strength of the convection and consequently impact the vertical development and the cloud properties. This warming might inhibit the entrainment of dry air at the top of the cloud, preserving the humidity of the cloud and increasing the liquid water content and the persistence of clouds (Johnson et al., 2004; Wilcox, 2010). Evi- dence of the first indirect effect was also found over the South Atlantic region, where AAC events are frequently observed. Costantino and Bréon (2013) notably found a strong decrease in the droplet effective radius when the aerosol layers are in contact with the top altitude of the cloud deck.

The scientific community is working on better monitoring the load and microphysical properties of AAC in order to assess the influence of those particles on the Earth's radiative budget and clouds. The constellation of satellites called the A-Train provides different passive and active sensors for monitoring clouds and aerosols (http://atrain.nasa. gov/publications/A-TrainFactSheet.pdf). Passive imagers offer larger spatial coverage but have no direct information of the vertical distribution of particles in the atmosphere. Active methods offer unique capabilities, complementary to the passive methods, and are dedicated to the study of the vertical profiles of clouds and aerosols. The main retrieved optical properties for aerosols, in "clear-sky" conditions, are the aerosol optical thickness (AOT) and the Ångström exponent $(\mathrm{AE})$, which is a parameter indicative of the particles size (Kaufman et al., 2002). Recent methods also allow retrieving the aerosol single scattering albedo (SSA) over clear-sky ocean scenes (Torres et al., 2013; Waquet et al., 2016).

The active sensor Cloud-Aerosol Lidar with Orthogonal Polarization (CALIOP) installed on CALIPSO (CloudAerosol Lidar and Infrared Pathfinder Satellite Observation) satellite provides high-resolution vertical profiles of aerosols and clouds (Chand et al., 2008; Winker et al., 2010). CALIOP provides the total attenuated backscatter signal $\left(\mathrm{km}^{-1} \mathrm{sr}^{-1}\right)$ at 532 and $1064 \mathrm{~nm}$. From the backscatter measurements, an operational aerosol algorithm allows for retrieval of the vertical extinction profiles as well as the AOT in clear and cloudy skies by assuming an aerosol lidar ratio (extinction to backscatter) (Omar et al., 2009; Young and Vaughan, 2009). Moreover, two orthogonally polarized channels measure the parallel and perpendicular backscatter signal at $532 \mathrm{~nm}$ that allows calculating the depolarization ratio (i.e. the ratio of the two orthogonal polarization signals) (Hunt et al., 2009). Depolarization measurements are used for discrimination between spherical and non-spherical particles (Sassen, 1991). CALIOP provides exhaustive details on the vertical distribution of optical and microphysical properties of aerosols and clouds, including their shape, and a qualitative classification of aerosol type (via the wavelength dependence of the backscatter) (Winker et al., 2009; Young and Vaughan, 2009).

Alternative CALIOP-based research methods have also been introduced to retrieve above-cloud AOT (ACAOT). The depolarization ratio method (DRM) (Hu et al., 2007a) and the colour ratio method (CRM) (Chand et al., 2008) use fewer assumptions for the retrieval of aerosol properties. These methods are based on light transmission methods and treat the liquid water clouds situated underneath the aerosol layer as a target. Hu et al. (2007b) have shown that, in the case of opaque water clouds, the layer-integrated attenuated 
backscatter at $532 \mathrm{~nm}$ and layer-integrated attenuated depolarization ratio at $532 \mathrm{~nm}$ can be used to retrieve the aerosol optical depth of the overlaying aerosol or optically thin cloud layers. The CRM uses the layer-integrated attenuated colour ratio, which is the ratio of integrated attenuated backscatter at 1064 to $532 \mathrm{~nm}$. Over the visible to near-infrared spectral region, fine-mode absorbing aerosols above clouds exhibit a strong wavelength dependence colour ratio (Chand et al., 2008). This makes possible the detection of absorbing biomass-burning aerosols transported above clouds. The colour ratio observed in the case of coarse-mode particles or purely scattering fine-mode aerosols transported above clouds exhibits little or no wavelength dependence and, thus, these particles can be less accurately detected with the CRM method.

Passive sensors have also been used to obtain information on aerosols above clouds. For example, Torres et al. (2012) have developed an algorithm to retrieve the ACAOT and the underlying aerosol-corrected cloud optical depth, using radiance measurements performed in the ultraviolet (UV) by the Ozone Monitoring Instrument (OMI). The method takes advantage of the ability of biomass-burning and mineral dust aerosols to strongly absorb UV radiations. Another method that can retrieve the ACAOT and, simultaneously, the aerosol-corrected cloud optical thickness (COT) is the "colour ratio" method proposed by Jethva et al. (2013) that employs measurements in visible and shortwave infrared channels from the Moderate Resolution Imaging Spectroradiometer (MODIS). Also, Meyer et al. (2015) developed an algorithm that employs reflectance measurements from six MODIS channels (from the visible to the shortwave infrared) to retrieve the ACAOT, as well as the COT and droplet effective radius $\left(r_{\text {eff }}\right)$ of the underlying cloud.

The multi-directional polarization measurements have shown sensitivity to AAC scenes (Waquet et al., 2009; Hasekamp, 2010; Knobelspiesse et al., 2011). The Polarization and Directionality of Earth Reflectances (POLDER) instrument is measuring the directionality and polarization of light reflected by the Earth-atmosphere system. The aerosols generate an additional polarized light at forward and side scattering angles (70-130 $)$ and reduce the polarized signal of the cloud bow (i.e. a strong polarized rainbow feature observed near $140^{\circ}$ in scattering angle). Mineral dust particles do not much polarize light, but they strongly minimize the cloud bow magnitude. Based on these effects, Waquet et al. (2009) have developed a method for retrieving the properties of aerosols above clouds that relies on the polarized radiances measured by POLDER. Because polarized radiances are not affected by the optical thickness of the cloud (i.e. the polarized radiance reflected by the cloud is saturated when the cloud is optically thick enough), the method is able to retrieve the scattering ACAOT at two wavelengths (670 and $865 \mathrm{~nm}$ ) without much assumption about cloud properties. An analysis of the global results obtained with the operational algorithm is given in Waquet et al. (2013a). Further- more, Peers et al. (2015) have developed a complementary method that uses additional total multidirectional radiances measured by POLDER. The method provides the aerosol SSA and the aerosol-corrected COT. So far, the algorithm of Peers et al. (2015) is a research method, only applied for regional studies (Peers et al., 2016).

Jethva et al. (2014) performed an intercomparative analysis of the ACAOT retrieved with the aforementioned methods in order to assess the consistency (or lack thereof) between the two independently derived ACAOTs. The results were encouraging and, despite the use of different assumptions and measurements, a close agreement was reported over homogeneous clouds. Similar to this study, our paper will focus on the comparison between collocated active and passive AAC inversion products, improving our understanding of the ACAOT. But, compared to Jethva et al. (2014), who focused only on two study cases, we perform a global and multi-annual investigation to provide robust statistics results. The vertical distribution of the aerosol and cloud layer will be also considered. We will concentrate on the following methods: (a) the CALIOP operational method (CALIOP OM $_{\text {) be- }}$ cause of the numerous studies in which it was used, (b) the DRM developed by $\mathrm{Hu}$ et al. (2007a), (c) a calibrated version of the DRM algorithm and (d) the POLDER polarization method. The DRM and POLDER methods were chosen because both are measuring AAC properties above the same type of cloudy scenes (i.e. optically thick and homogeneous liquid water clouds). Moreover, both techniques are sensitive to all types of particles (scattering or absorbing particles, fine or coarse ones), which is not the case for CRM, which can operate only for absorbing aerosols. It is also interesting to compare these two approaches since the POLDER method requires a hypothesized aerosol microphysics, while DRM does not require any hypothesis for the aerosols but does require assumptions and an approximate model to estimate the signal backscattered by clouds.

To begin with, we briefly recall the principle of each algorithm and the data selection strategy. The results of AOT intercomparison are presented in Sects. 3 and 4. We first present a regional comparison and then describe a global comparison for a period of 4.5 years in function of the type of aerosols and AAC scenes (aerosol and cloud layers in contact or well separated). Discussions and conclusions will be drawn in Sects. 5 and 6.

\section{Methodology and data selection}

\subsection{POLDER polarization method}

POLDER, an instrument on the PARASOL (Polarization and Anisotropy of Reflectances for Atmospheric Science coupled with Observations from a Lidar) satellite, is a wide-field imaging radiometer/polarimeter (Tanré et al., 2011). This instrument measures the angular and spectral behaviour of 
the normalized total and polarized radiances (Herman et al., 2005).

The method for retrieving the above-cloud scattering AOT developed by Waquet et al. (2013b) consists of a comparison between polarized radiances measured by POLDER at 670 and $865 \mathrm{~nm}$ and polarized radiances pre-computed with a successive order of scattering (SOS) code (Deuzé et al., 1989) for seven aerosol models that follow a single lognormal size distribution. Six models correspond to spherical aerosols (fine-mode particles) with radius from 0.06 to $0.16 \mu \mathrm{m}$, for which a complex refractive index of $1.47-0.01 i$ is assumed. The seventh model is bimodal and characteristic of non-spherical aerosols (dust) with a refractive index of $1.47-0.0007 i$. In the search for the best-fitting aerosol model, the operational algorithm follows the strategy described by Waquet et al. (2013b). After a first step, the algorithm produces an approximation of the AOT at $865 \mathrm{~nm}$. As a function of this AOT value, a decision tree is applied: if the AOT is larger than 0.1 then the algorithm will search the best-fitting model within all the seven models without any angular constraint for the selection of the POLDER data (scattering angle ranging from 0 to $180^{\circ}$ ). Next, if the mineral dust model fails to reproduce the data or if the AOT retrieved in the first step is smaller than 0.1, then only fine-mode models are considered in the retrieval scheme and the viewing geometries are restricted to side or forward viewing geometries (scattering angles smaller than $130^{\circ}$ ). The AOT threshold of 0.1 at $865 \mathrm{~nm}$ is empirical and was introduced since the retrieval of the aerosol type (dust or fine-mode particles) becomes difficult for small AOT.

Collocated cloud properties retrieved from MODIS at high resolution $\left(1 \times 1 \mathrm{~km}^{2}\right.$ at nadir $)$ are used to characterize and to select the cloudy scenes within a POLDER pixel $(6 \mathrm{~km} \times 6 \mathrm{~km}$ at nadir). We only consider fully covered cloudy pixels associated with optically thick liquid water clouds: the COT retrieved by MODIS has to be larger than 3 and a cloud phase algorithm is applied to select liquid water clouds (Riedi et al., 2010). Moreover, Waquet et al. (2013b) have introduced a mask to eliminate cirrus above liquid clouds that makes use of the MODIS brightness temperature difference (BTD) between 8.5 and $11 \mu \mathrm{m}$ wavelength bands as well as MODIS and POLDER cloud top pressure estimates. Lastly, the AOT retrievals at the $6 \mathrm{~km} \times 6 \mathrm{~km}$ spatial resolution are aggregated to $18 \mathrm{~km} \times 18 \mathrm{~km}$ spatial grid. The retrieved solution is kept if the number of $6 \mathrm{~km} \times 6 \mathrm{~km}$ pixels is larger than 5 and if the standard deviation computed for the mean AOT is smaller than 0.1. This latter procedure allows to remove edges of clouds. In our study, we use the version 3.00 of the official output product PARASOL_PM02-L2 for AAC scenes available at ICARE website (http://www.icare. univ-lille1.fr/parasol/products/).

\subsection{CALIOP methods}

\subsubsection{Operational method}

The CALIPSO lidar (CALIOP) is a frequency-doubled Nd:YAG laser, dual-wavelength, dual-polarization, elastic backscatter lidar (Winker et al., 2009). The lidar returned signal is normalized and range-corrected to provide the total attenuated backscatter coefficient $\left(\mathrm{km}^{-1} \mathrm{sr}^{-1}\right)$.

In order to retrieve the attenuated backscatter data and the columnar AOT at 532 and $1064 \mathrm{~nm}$, the operational CALIOP algorithm combines the feature and layer detection scheme (Vaughan et al., 2009) with the extinction retrieval algorithm (Young and Vaughan, 2009) that employs assumptions on the extinction-to-backscatter ratio of aerosols. There are several steps involved in the operational data processing: (1) cloud and aerosol layers are detected in the backscattered signal along with their altitudes; (2) the algorithm determines which layers have cloud or aerosol features; (3) the cloud ice-water phase is estimated and the aerosol lidar ratio is determined, using assumptions on the aerosol models; and finally (4) the extinction coefficients and AOT are retrieved at 532 and $1064 \mathrm{~nm}$.

Lidar systems have a limited capability to determine the composition and size of aerosols. Hypotheses are then used on the aerosol phase function at $180^{\circ}$ and on the aerosol SSA in order to calculate the aerosol lidar ratio. In the operational algorithm, the aerosol models consist in a mixture of aerosol components characteristic of a region or an air mass. It should be noted that an incorrect assumption for the lidar ratio could be a source of substantial errors in the AOT retrieved with this method.

For our study we use the level 2 version 3.01 of the inversion products, officially named CAL_LID_L2_05kmALay (ALay) and CAL_LID_L2_05kmCLay (CLay) (which can be found at http://www.icare.univ-lille1.fr/calipso/ products/), which provide, respectively, the aerosol and cloud layer parameters at a nominal horizontal resolution of $5 \mathrm{~km}$. From these products we used the AOTs retrieved at 532 and $1064 \mathrm{~nm}$, the aerosol base and top altitudes, the cloud top altitude, the ice-water cloud phase and the feature type. We also use CALIOP level 1 dataset, labelled CAL_LID_L1-ValStage1 (link above), which provides the attenuated backscatter coefficient calculated at a vertical resolution of $30 \mathrm{~m}$ from -0.5 to $8.2 \mathrm{~km}$ altitude and at $333 \mathrm{~m}$ horizontal resolution (Winker et al., 2007).

\subsubsection{Depolarization ratio method}

For retrieving the optical thickness of a thin high layer (aerosols or clouds) above a lower and optically thick water cloud layer, Hu et al. (2007a) and Chand et al. (2008) describe the depolarization ratio method applied to CALIOP measurements. An opaque cloud with a minimum optical depth of 3 will attenuate the lidar beam completely. For op- 
tically thick clouds, we estimate the optical thickness of the above thin aerosol or cloud layer by treating the opaque cloud as a target and by using the Beer-Lambert law to estimate the direct transmission of light above this cloud layer. We will refer to this product hereafter as $\mathrm{DRM}_{\mathrm{Hu}}$.

The physical properties used in this method are the cloud attenuated backscatter coefficient $\left(\gamma^{\prime}{ }_{\text {water }}\right)$ integrated from the base to the top of the cloud layer at $532 \mathrm{~nm}$ and the integrated attenuated depolarization ratio $\left(\delta^{\prime}\right)$ at $532 \mathrm{~nm}$. When Rayleigh scattering contribution has been corrected for, the definition of $\gamma^{\prime}$ water is given by the following equation:

$\gamma_{\text {water }}^{\prime}=\int_{z_{-} \text {top }}^{z_{-} \text {base }} \beta^{\prime}(z) \mathrm{d} z$,

where $\beta^{\prime}$ is the total attenuated backscatter coefficient $\left(\mathrm{km}^{-1} \mathrm{sr}^{-1}\right)$.

In situations where the cloud is optically thick and there are no aerosols above the cloud, the lidar equation simplifies to the following definition, expressed as a function of the lidar ratio $\left(S_{\mathrm{c}}\right)$ and layer-effective multiple scattering factor $\left(\eta_{\mathrm{c}}\right)$ (Platt, 1979):

$\gamma_{\text {water, calc }}^{\prime}=\int_{z_{-} \text {top }}^{z_{\text {_base }}} \beta^{\prime}(z) \mathrm{d} z=\left(2 \eta_{\mathrm{c}} S_{\mathrm{c}}\right)^{-1}$.

$S_{\mathrm{c}}$ is narrowly constrained to about $19 \mathrm{sr}$ at a wavelength of $532 \mathrm{~nm}$. This value is typically used for liquid water clouds with droplets smaller than about $50 \mu \mathrm{m}$ (O'Connor et al., 2004; Pinnick et al., 1983). $\eta_{\mathrm{c}}$, which takes a value between 0 and 1 , is strongly related to the cloud depolarization ratio $\delta^{\prime}$ (defined as the ratio of the parallel and perpendicular polarization signals), since multiple scattering processes tend to depolarize light. An approximate relation was derived from Monte Carlo simulations (Hu et al., 2006):

$\eta_{\mathrm{c}}=\left(\frac{1-\delta^{\prime}}{1+\delta^{\prime}}\right)^{2}$.

After $\gamma^{\prime}$ water is corrected for molecular and gaseous attenuation, the ratio between $\gamma^{\prime}{ }_{\text {water }}$ and $\gamma^{\prime}$ water,calc should be equal to 1 in the absence of higher aerosol or cloud layer and have an accurate lidar calibration. Instead, in case of an overlying aerosol or cloud layer, this ratio can be written as

$\frac{\gamma^{\prime}{ }_{\text {water }}}{\gamma^{\prime}{ }_{\text {water,calc }}}=T^{2}=\exp \left(-2 \tau_{\text {top,DR }}\right)$,

where $T^{2}$ is the transmission of light after a two-way propagation between the sensor and the targeted cloud, and $\tau_{\text {top,DR }}$ is the higher layer's optical thickness. It follows from Eq. (4) that the optical depth $\left(\tau_{\text {top,DR }}\right)$ is given by

$\tau_{\text {top, DR }}=\frac{-1}{2} \ln \left(2 S_{\mathrm{c}} \gamma^{\prime}{ }_{\text {water }} \eta_{\mathrm{c}}\right)$.
$\mathrm{DRM}_{\mathrm{Hu}}$ differs from the operational method by the fact that it does not rely on assumptions related to aerosol microphysical properties (aerosol phase function and SSA) and does not require accurate layer detection for the overlying aerosol layer in order to estimate the AOT integrated over the atmospheric column. The main uncertainties of the $\mathrm{DRM}_{\mathrm{Hu}}$ are linked to the calibration of the lidar, which impact the estimate of the parameters in Eq. (5).

Providing a robust, self-calibrated method at global scale and for the whole CALIPSO dataset is not trivial and, in order to improve the estimate of the AOT with the DR method, the developers of the Synergized Optical Depth of Aerosols and ICE clouds (SODA \& ICE, available at the ICARE thematic centre), Josset et al. (2010, 2012), modified the original formalism of $\mathrm{DRM}_{\mathrm{Hu}}$. The main reason for these modifications is that the relationship between the multiple scattering factor and the depolarization by the cloud shows a systematic deviation from the theory (see Fig. 2 in $\mathrm{Hu}, 2007$ ). The multiple scattering-depolarization relationship has been confirmed by laboratory experiments (Cao et al., 2009). Even if it has to be modified in the presence of submicrometer or non-spherical particles, the origin of the discrepancy between theory and observation points towards an instrumental issue. The long transient response of the receiver has been proposed as an explanation and a correction was also proposed (Hu et al., 2007b). There are, however, other issues related to the calibration of the polarization channel that could explain the discrepancy. The low gain-high gain merging scheme and the day-night calibration transfer are a significant source of uncertainty. Previous research (Sassen and Zhu, 2009) found a bias in the linear depolarization of cirrus clouds of around $30 \%$.

In order to overcome these difficulties and improve the accuracy of the method, SODA takes advantage of the high number of CALIOP observations of liquid water clouds in the absence of AAC. Practically, the SODA algorithm introduces global-scale correction factors in the multiple scattering coefficient to depolarization relationship and a recalibrated value of the liquid water cloud lidar ratio as a function of latitudes. These two corrections come from the fact that, when the liquid water clouds are optically dense and in absence of $\mathrm{AAC}$, the lidar equation can be reduced to Eq. (2). Over the ocean, the lidar ratio of most liquid water clouds is relatively constant (Hu et al., 2006) and the multiple scattering coefficient can be measured directly if the lidar is well calibrated. This correction follows the original intent of $\mathrm{DRM}_{\mathrm{Hu}}$ (Hu et al., 2007a), which has always been to be a self-calibrated method, unaffected by instrumental or geophysical uncertainties (see Eq. 4 of $\mathrm{Hu}$ et al., 2007a, and related discussion). However, because the discrepancy between theory and observations is due to an instrumental artefact linked to the receiver electronics, SODA introduces a clearer separation between the parallel and perpendicular channel than in $\mathrm{DRM}_{\mathrm{Hu}}$ (Hu et al., 2007b). $\mathrm{DRM}_{\mathrm{Hu}}$ relates the total backscatter coefficient to the ratio of perpendicu- 
lar and parallel backscatter coefficient while SODA links the parallel backscatter coefficient to this ratio. This approach is supported by the theory of light propagation in dense medium where the contribution of multiple scattering to the perpendicular and parallel channel is identical (Xu and $\mathrm{Al}-$ fano, 2005) and by the analysis of CALIOP data.

A preliminary and mandatory step of the calibration procedure is to select optically opaque liquid water clouds with no AAC. The calibration modules of SODA use the following criteria. Note that there is some level of redundancy in order to increase data quality selection.

a. Criteria of optical density:

- The top and bottom of the cloud is given by the $333 \mathrm{~m}$ CALIPSO cloud product. This ensures a minimum level of signal strength and the presence of a transparent atmosphere above it. Note that SODA corrects the molecular attenuation above the cloud but does not contain an explicit correction of it within the cloud because of the high scattering ratio of liquid water clouds. Nonetheless, the molecular contribution is statistically taken into account by the calibration procedure.

- The maximum of the lidar signal is above the base of the cloud. This ensures an adequate level of attenuation of the surface return.

- The ocean surface integrated attenuated backscatter is below a detectability threshold of $7.5 \times 10^{-6} \mathrm{sr}^{-1}$ for nighttime data and $1 \times 10^{-3} \mathrm{sr}^{-1}$ for daytime data. This corresponds to a COT of around 2 during daytime and $4-5$ during nighttime, which is when this filter is the most useful. The intent of this threshold is the same as the previous criteria. More specifically, the goal is to use a threshold such that half the shots are below the noise sensitivity of the instrument.

b. Criteria of cloud in liquid phase:

- The temperature at the top of the cloud is higher than $0^{\circ} \mathrm{C}$. The isotherm is defined by the GMAO (Global Modelling and Assimilation Office) temperature when interpolated on the CALIPSO vertical grid.

- The total cloud liquid water contained in a vertical column of atmosphere retrieved from collocated pixels of AMSR-E/AMSR2 is larger than $0 \mathrm{~mm}$.

c. Criteria of clear air above the cloud:
- The total $532 \mathrm{~nm}$ integrated attenuated backscatter coefficient from $20 \mathrm{~km}$ of altitude to the top of the cloud is below the following threshold:

$$
\int_{z \_ \text {top }}^{20 \mathrm{~km}} \beta^{\prime}(z) \mathrm{d} z<\frac{1-\exp \left(-2 \tau_{\mathrm{air}, \mathrm{mol}}\right)}{2 \frac{8 \pi}{3} 1.5},
$$

where $\tau_{\text {air,mol }}$ is the optical depth due to air Rayleigh scattering and ozone absorption. The factor of 1.5 allows the reduction of occurrences of false positives due to noise. It also allows us to simplify the formalism as the King factor (Bates, 1984; King, 1923) can be neglected with no expected impact on the results. As this filter introduces more aerosol contamination during daytime (similar to Josset et al., 2010, Fig. 4), it could be desirable to consider the shot-to-shot CALIOP cloud mask for future version of the algorithm as SODA already uses this information for the scene classification flag.

As previously mentioned, even if the multiple scatteringdepolarization relationship has been confirmed by laboratory experiments (Cao et al., 2009), the relationship between the multiple scattering factor and the depolarization by the cloud shows a systematic deviation from the theory. It has to be corrected, as it would introduce a bias in aerosol optical depth with the particularly undesirable trait to correlate with cloud microphysical properties. As a first step, SODA calibrates the multiple scattering to depolarization relationship for nighttime data on a monthly basis. The data of interest are based on Eq. (2) and can be written as

$\eta_{\text {geo }}=\frac{1}{2 \times 19 \times \gamma^{\prime}{ }_{\text {water,parallel }}}$,

where $\gamma^{\prime}$ water,parallel is the parallel-integrated backscatter coefficient. This equation provides a direct measurement of the multiple scattering coefficient of liquid water clouds $\left(\eta_{\mathrm{geo}}\right)$ when their lidar ratio is constant. The constant value of $19 \mathrm{sr}$ used in the SODA algorithm is based on Hu et al. (2006), who found a lidar ratio equal to $19.1 \pm 0.21 \mathrm{sr}$ when the 41 droplet size distributions of Miles et al. (2000) are used as inputs of a Mie scattering code.

For all opaque liquid water clouds defined with the above criteria, SODA then compares the direct measurement of the multiple scattering coefficient $\left(\eta_{\text {geo }}\right)$ and the theory $\left(\eta_{\mathrm{c}}\right)$ to find the second-order polynomial that best fit the data in the least-squares fit sense. This defines the calibrated multiple scattering coefficient $\left(\eta_{\text {calibr }}\right)$ :

$\eta_{\text {calibr }}=\operatorname{fit}\left[\eta_{\text {geo }}\left(\eta_{\mathrm{c}}\right)\right]=A \eta_{\mathrm{c}}+B \eta_{\mathrm{c}}^{2}$.

This procedure allows us to use a relationship between depolarization and multiple scattering that fits the observation. 
Using Eq. (3) instead of Eq. (8) would create an aerosol optical depth bias that would typically range between 0.02 and 0.08. Although this is not always significant, this correction is necessary as the resulting ACAOT bias does correlate with the cloud's microphysical properties. This is particularly undesirable as the link between aerosol and cloud microphysical properties is an active topic of research.

As a second step, SODA calculates the apparent lidar ratio $S_{\mathrm{c}, \text { lat }}$ of all opaque liquid water clouds as a function of each degree of latitude and for both 532 and $1064 \mathrm{~nm}$. This procedure is done separately for daytime and nighttime data. The latitudinal dependency aims to correct the calibration inaccuracies of CALIOP, which are dependent on latitude (Powell et al., 2010) and possible geophysical variations of cloud microphysical properties between the northern and southern hemispheres.

$S_{\mathrm{c}, \text { lat }}=\frac{1}{2 \times \eta_{\text {calibr }} \times \gamma^{\prime}{ }_{\text {water,parallel }}}$

For the 4.5 years of data we considered in this study, the median of $S_{\mathrm{c} \text {,lat }}$ for the nighttime data is $19.36 \mathrm{sr}$, which is interestingly close from the theoretical value determined by $\mathrm{Hu}$ et al. (2006). For daytime data, $S_{\mathrm{c}, \text { lat }}$ is systematically higher and with a median of $20.64 \mathrm{sr}$. The systematic daytime-nighttime difference could be geophysical. However, it is premature to reach such conclusion until all nighttime-daytime differences in the CALIPSO data have been addressed.

Lastly, all these coefficients are finally integrated in the AOT retrieval equation:

$\tau_{\text {top,DRcalibr }}=-\frac{1}{2} \ln \left(2 S_{\mathrm{c}, \text { lat }} \eta_{\text {calibr }} \gamma_{\text {water,parallel }}^{\prime}\right)$,

Throughout this study, we will refer to this product as DRM $_{\text {SODA }}$, which can be found at ICARE Data and Services Center (http://www.icare.univ-lille1.fr/projects/soda/).

\subsection{Data selection}

\subsubsection{Collocation}

The A-Train satellites pass through close orbits within several minutes, providing coincident observations of POLDER, MODIS and CALIOP instruments. Using the nearest pixel approximation, CALIOP files are used as a space reference for sampling POLDER and MODIS products. CALTRACK is the output dataset and can be found at ICARE. It contains coincident data from POLDER at $18 \mathrm{~km} \times 18 \mathrm{~km}$ and MODIS, extracted under the CALIOP track at $5 \mathrm{~km}$ horizontal resolution. The $\mathrm{DRM}_{\mathrm{Hu}}$ and DRM $\mathrm{SODA}_{\mathrm{S}}$ optical depth retrievals are processed at the CALIOP native resolution of $333 \mathrm{~m}$ and aggregated afterwards at $5 \mathrm{~km}$ horizontal resolution. Moreover, for a better consistency of the AOT comparison, the POLDER AOT was extrapolated at $532 \mathrm{~nm}$ using the $\mathrm{AE}$ retrieved with the POLDER algorithm.
We also limited the cloud top altitude at $5 \mathrm{~km}$ because we are interested in low-level clouds. Likewise, we eliminated from our data analysis all situations in which the aerosol top altitude exceeds $10 \mathrm{~km}$. This maximal value should be sufficient, since most of the biomass-burning and dust aerosol layers are typically observed between 0.5 and $4.0 \mathrm{~km}$ over ocean (Torres et al., 2013).

\subsubsection{Distinction between vertical profiles}

Additionally, we have employed an approach that is similar to the concept of Costantino and Bréon (2013) to classify the type of AAC scenes. The respective positions of the aerosol and cloud layers are defined using the CALIOP ALay and CLay products. We classify the AAC scenes into three categories: "attached", "detached" and "undetermined". The socalled "attached cases" correspond to situations where the aerosol layer touches the top of the beneath cloud layer. For these cases, we assume that the vertical distance of the aerosol bottom altitude from cloud top altitude must be lower than $100 \mathrm{~m}$, without penetrating the cloud layer for more than $50 \mathrm{~m}$. Inversely, the "detached cases" correspond to aerosol and cloud layers that are considered well separated, considering a distance higher than $500 \mathrm{~m}$ between the aerosol base altitude and the cloud top. Aerosol layers with the base altitude within a distance between 100 and $500 \mathrm{~m}$ above the cloud layer are considered too uncertain and are excluded from our study. We also removed the situations for which the detected CALIOP aerosol top and/or bottom altitudes are located below the cloud top, assuming that these data are highly uncertain. Practically, we rejected the CALIOP data for which the aerosol layer penetrates the cloud layer by more than $50 \mathrm{~m}$. The third category, "undetermined", corresponds to situations for which the respective position of the aerosol or cloud layer is not identified by the CALIOP layer detection algorithm (i.e. missing data), even though POLDER and DRM AAC AOT retrievals are valid. We chose to keep these data in our analysis as they cover the majority of POLDER AAC detected cases with a non-negligible AOT (even if CALIOP classifies them as invalid or noise), as the purpose of the paper is to better understand the differences between the methods.

We also distinguish the "two-layer situation" (i.e. one aerosol layer and one cloud layer) from the "multiple-layer situations" (more than one aerosol layer and/or more than one cloud layer). These latter situations are filtered in our analysis for the sake of simplicity (see Sects. 3.4 and 4).

\section{Regional analysis and case studies}

The results presented in this section were acquired from May to October 2008. We selected three distinctive regions (see Fig. 2) that are under the influence of various aerosol species and different types of clouds: (a) an area that extends from 

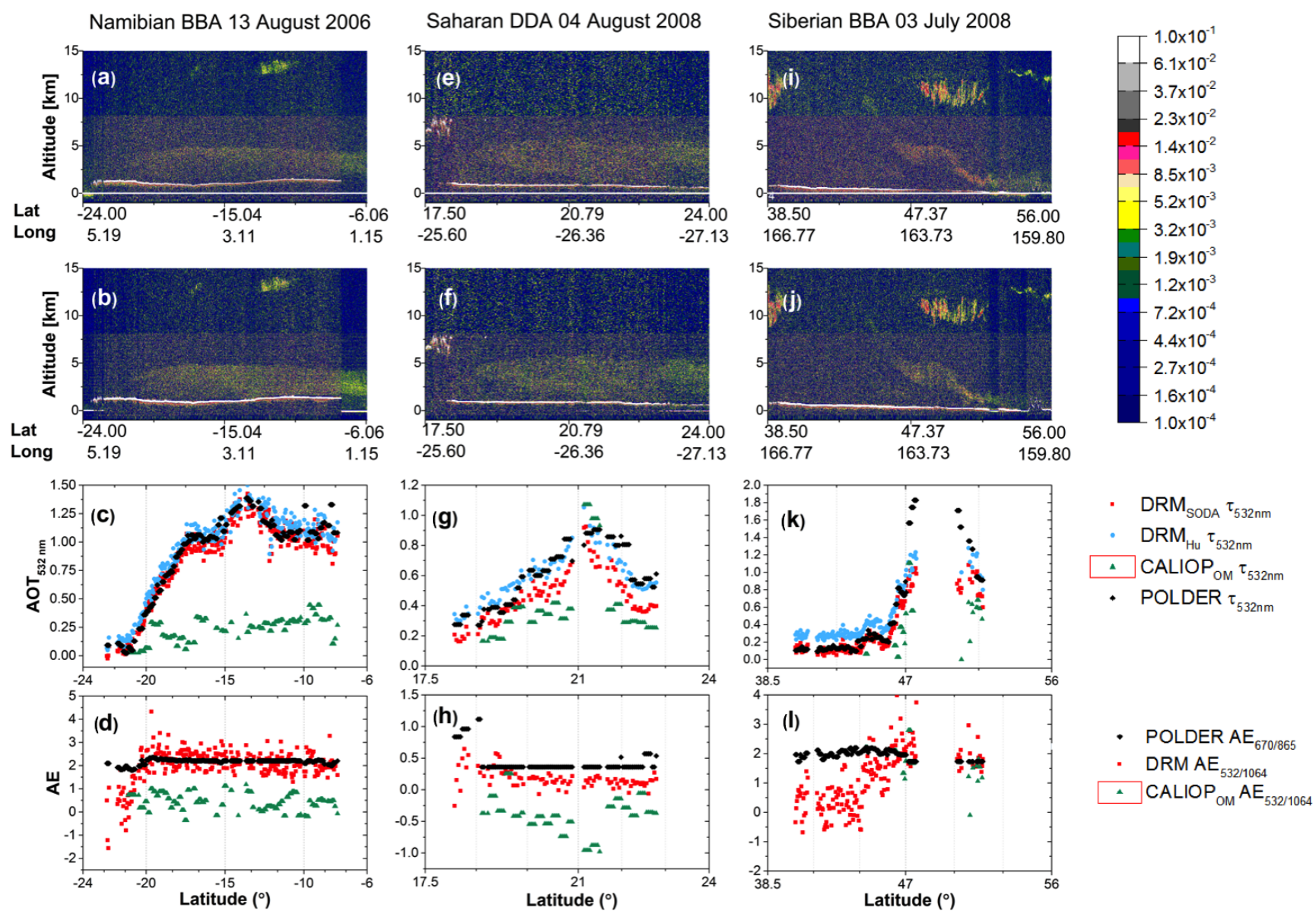

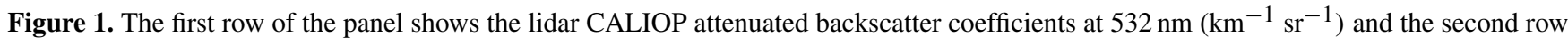
presents the CALIOP attenuated backscatter coefficients at $1064 \mathrm{~nm}$ for three case studies: African biomass-burning aerosols (BBA) above clouds on 13 August 2006 (a-d), Saharan dust (DDA) on 4 August 2008 (e-h) and Siberian biomass-burning aerosols over the Okhotsk Sea on 3 July 2008 (i-l). For these cases, the above-cloud AOT at $532 \mathrm{~nm}$ and the Ångström exponent (AE) as a function of latitude, measured with several techniques, are displayed.

$30^{\circ} \mathrm{S}$ to $5^{\circ} \mathrm{N}$ and $12^{\circ} \mathrm{W}$ to $14^{\circ} \mathrm{E}$ over the South Atlantic Ocean (SAO), (b) an area between 10 and $35^{\circ} \mathrm{N}$ and 10 and $40^{\circ} \mathrm{W}$ over the North Atlantic Ocean (NAO) and (c) an area located between 35 and $60^{\circ} \mathrm{N}$ and 140 and $170^{\circ} \mathrm{E}$ over the North Pacific Ocean (NPO). The south of the African continent is the main contributor to biomass-burning aerosols above clouds, originating from manmade crops fires (Waquet et al., 2013b). These aerosols are highly absorbing (SSA of approximately 0.84 at $865 \mathrm{~nm}$ ) and associated with high AE values; they mainly contribute to the fine mode. The NAO area is mainly under the influence of dust aerosols originating from the Sahara for the time period of interest. These particles are mainly non-spherical and contribute primary to the coarse mode. They are moderately absorbing at the wavelength of CALIOP $(532 \mathrm{~nm})$ and almost non-absorbing at $865 \mathrm{~nm}$ (SSA of approximately 0.98) (Balkanski et al., 2007; Dubovik et al., 2002; Peers et al., 2015). The NPO is associated with various types of particles: fine-mode aerosols with rather scattering properties originating from manmade pollution (Waquet et al., 2013a; Yu et al., 2008), biomass burning from forest fires (Peers et al., 2015; Zhang et al., 2003) and dust originated from the Asian deserts. Potential mixture of these different species is also possible for this area (Yu et al., 2006).

Cloud types and their associated optical and microphysical properties are expected to be different in these three regions (Warren et al., 1988). Low-level stratocumulus clouds typically cover the SAO, with some occurrences of cumulus and altostratus clouds. Cumulus, altostratus clouds and some stratocumulus clouds generally cover the NAO. The cloud cover is generally fractional over this part of the Atlantic Ocean. Stratocumulus clouds also frequently cover the NPO. Higher altostratus and cumulus clouds are also often observed over this area. Cirrus clouds can be frequently found at mid-latitudes and also in the intertropical convergence zone, which includes the NPO and the NAO regions. 
Table 1. Linear regressions of AOT calculated between different methods for three case studies: African biomass-burning aerosols (BBA), Saharan dust aerosols (DDA) and Siberian BBA. $R^{2}$ represents the coefficient of determination (COD) between the two sets of data.

\begin{tabular}{llrrr}
\hline Linear regressions & & $\begin{array}{r}\text { African BBA } \\
(13 \text { Aug 2006) }\end{array}$ & $\begin{array}{r}\text { Saharan DDA } \\
\text { (4 Aug 2008) }\end{array}$ & $\begin{array}{r}\text { Siberian BBA } \\
\text { (3 Jul 2008) }\end{array}$ \\
\hline DRM $_{\text {SODA vs. POLDER }}$ & Slope & $0.89 \pm 0.01$ & $0.74 \pm 0.04$ & $0.56 \pm 0.01$ \\
& Intercept & $0.04 \pm 0.01$ & $0.01 \pm 0.02$ & $0.07 \pm 0.009$ \\
& $R^{2}$ (COD) & 0.93 & 0.79 & 0.90 \\
\hline DRM $_{\text {Hu vs. POLDER }}$ & Slope & $0.91 \pm 0.01$ & $0.74 \pm 0.03$ & $0.60 \pm 0.01$ \\
& Intercept & $0.11 \pm 0.01$ & $0.15 \pm 0.02$ & $0.23 \pm 0.009$ \\
& $R^{2}$ (COD) & 0.93 & 0.82 & 0.89 \\
\hline CALIOP $_{\text {OM vs. POLDER }}$ Slope & $0.19 \pm 0.01$ & $0.86 \pm 0.11$ & $0.47 \pm 0.08$ \\
& Intercept & $0.05 \pm 0.01$ & $-0.16 \pm 0.07$ & $-0.04 \pm 0.08$ \\
& $R^{2}$ (COD) & 0.35 & 0.41 & 0.45 \\
\hline
\end{tabular}

We studied 6 months of data over each region to observe the consistency between different techniques for various types of aerosols. For this part of the study, we mixed the two-layer and multiple-layer situations and we analysed all the data, disregarding the position of the aerosol and cloud layers. A case study was selected for each region in order to show the spatial variability of the AOT at $532 \mathrm{~nm}$ retrieved along the CALIOP transect. The first case is related to a biomass-burning event detected off the coast of Namibia on 13 August 2006. The second event concerns Saharan dust lifted above clouds westwards over the NAO on 4 August 2008, and the third case concerns Siberian biomass-burning aerosols transported over the Okhotsk Sea on 3 July 2008.

Figure 1 presents the backscatter profile at $532 \mathrm{~nm}$ and at $1064 \mathrm{~nm}\left(\mathrm{~km}^{-1} \mathrm{sr}^{-1}\right)$ of the lidar CALIOP for the three case studies, which directly provides information on the aerosol and cloud vertical distribution. In addition, the AOT and AE values measured by different techniques are presented along the CALIOP track. Additional results for the study cases comparison are shown in Table 1.

Figure 3 shows the regional comparison between the AOT and AE retrieved with POLDER and DRM SODA $_{\text {for a period }}$ of 6 months in 2008. The retrieval of aerosol type becomes difficult at small AOT. Therefore the AE comparison was performed only when the values of POLDER AOT at $865 \mathrm{~nm}$

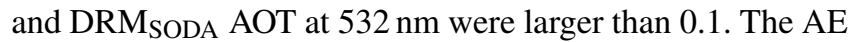
mean value is shown with a dashed blue line. The lateral histograms show the data distribution. For the AOT comparison the colour scale represents the POLDER $\mathrm{AE}_{670 / 865}$. In the case of AE comparison, the POLDER AOT $532 \mathrm{~nm}$ was also reported with a colour scale. The above-mentioned description is also considered in Fig. 4, which presents the regional comparison between the AOT and AE retrieved with POLDER

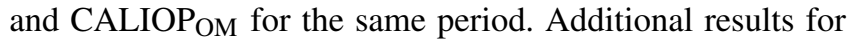
the regional intercomparison are reported in Table 2.

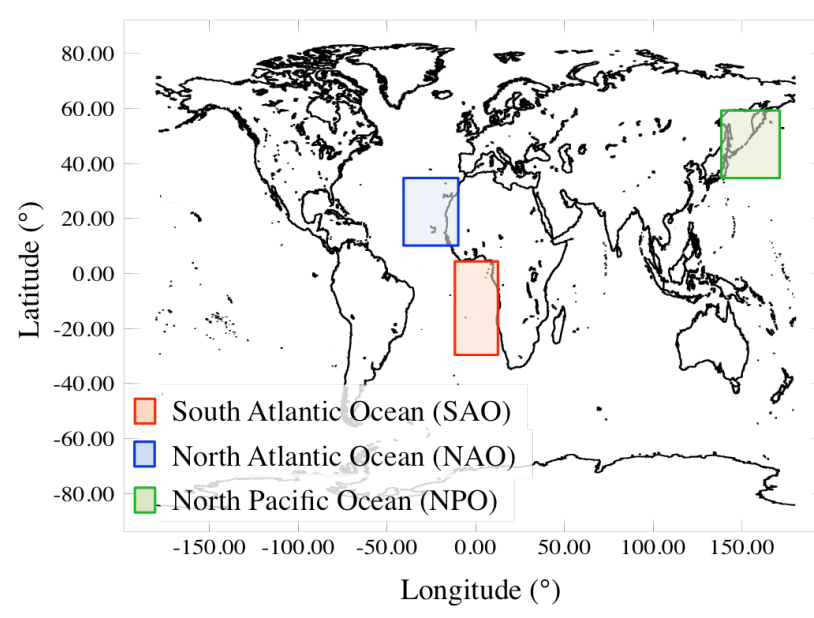

Figure 2. The map presents the latitudinal and longitudinal boundaries of the three regions used in the regional study (Sect. 3): South Atlantic Ocean (SAO) extends from $30^{\circ} \mathrm{S}$ to $5^{\circ} \mathrm{N}$ and $12^{\circ} \mathrm{W}$ to $14^{\circ} \mathrm{E}$, North Atlantic Ocean (NAO) is situated between 10 and $35^{\circ} \mathrm{N}$ and 10 and $40^{\circ} \mathrm{W}$ and North Pacific Ocean (NPO) is located between 35 and $60^{\circ} \mathrm{N}$ and 140 and $170^{\circ} \mathrm{E}$.

\subsection{African biomass-burning aerosols}

According to the CALIOP vertical profile at $532 \mathrm{~nm}$ of the biomass-burning case (Fig. 1a), the cloud top is at around $1.5 \mathrm{~km}$ and the aerosol layer is located between 3 and $5 \mathrm{~km}$. The $1064 \mathrm{~nm}$ backscatter profile (Fig. 1b) exhibits an aerosol layer with a larger vertical extent, showing more potential contact area with the underlying cloud. We observe a thin cirrus cloud between 10 and $12^{\circ} \mathrm{S}$ that was not filtered, probably because the cirrus is optically too thin (Fig. 1c and d). In general, there is an excellent agreement between POLDER, DRM $\mathrm{Hu}_{\mathrm{H}}$ and DRM $\mathrm{SODA}$ AOT retrievals with a square correlation $R^{2}=0.93$ (see Table 1 ). High values of AOT are retrieved by the different methods, with AOT values as large as 1.5. The retrieved POLDER $\mathrm{AE}_{670 / 865}$ is larger 

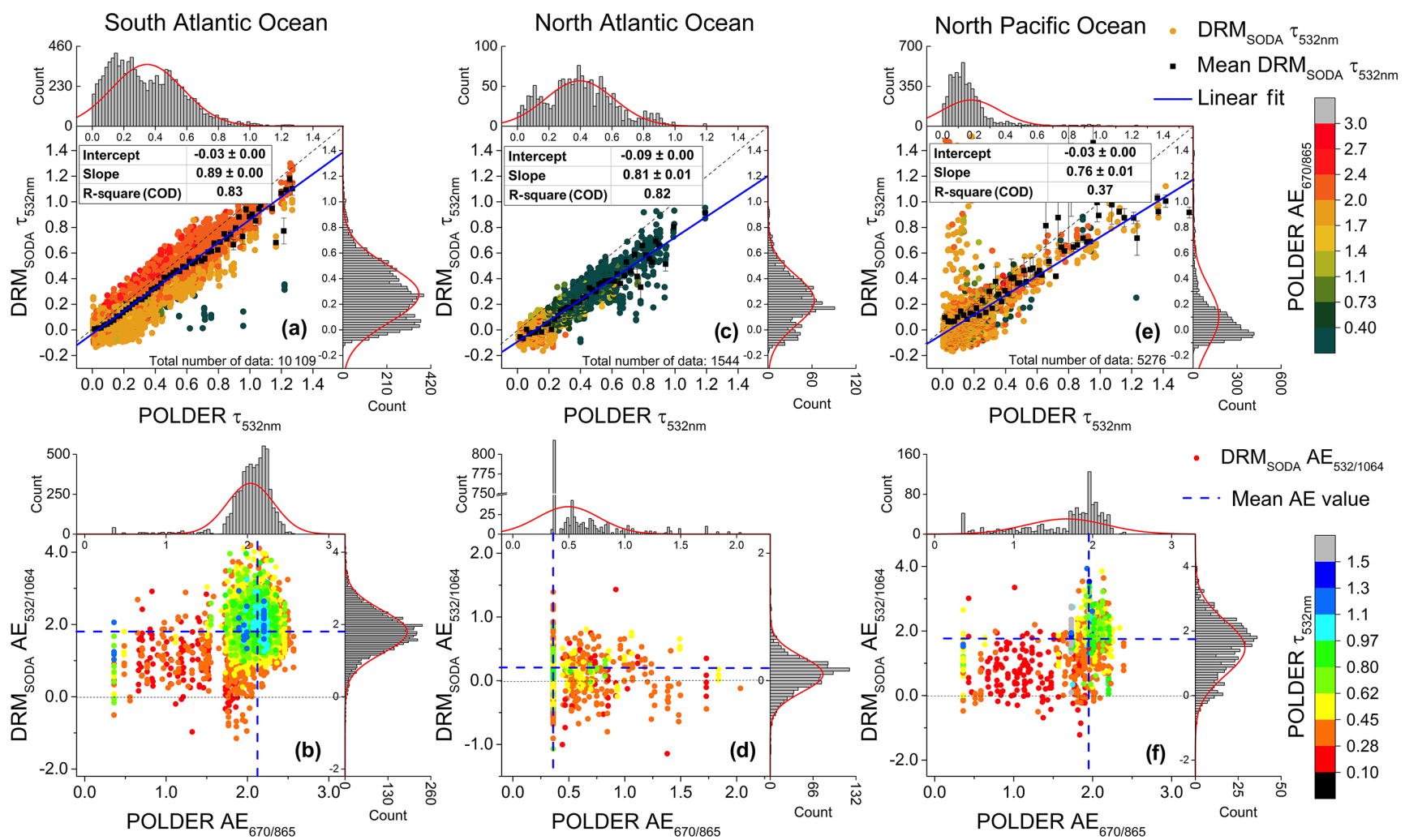

Figure 3. The first row of the panel shows the comparison of AOT at $532 \mathrm{~nm}$ retrieved from DRM SODA and POLDER methods, with the corresponding POLDER AE colour scale, computed between 670 and $865 \mathrm{~nm}$. The second row presents the Ångström exponent comparison for AOTs larger than 0.1, retrieved from DRM SODA and POLDER methods, with the corresponding POLDER AOT at $532 \mathrm{~nm}$ colour scale. The measurements were made over a period of 6 months (May to October 2008) and over three distinctive regions: South Atlantic Ocean, between $30^{\circ} \mathrm{S}$ and $5^{\circ} \mathrm{N}$ and $12^{\circ} \mathrm{W}$ and $14^{\circ} \mathrm{E}$ (a, b); North Atlantic Ocean, between 10 and $35^{\circ} \mathrm{N}$ and 10 and $40^{\circ} \mathrm{W}$ (c, d); and North Pacific Ocean, between 35 and $60^{\circ} \mathrm{N}$ and 140 and $170^{\circ} \mathrm{E}(\mathbf{e}, \mathbf{f})$. The histograms present the data distribution. The error bars in (a), (c) and (e) represent the standard error of the mean (SEM).

Table 2. Linear regressions of AOT calculated between different methods for data acquired over 6 months (May to October 2008), over three different regions: South Atlantic Ocean (SAO), North Atlantic Ocean (NAO) and North Pacific Ocean (NPO).

\begin{tabular}{|c|c|c|c|c|}
\hline Linear regressions & & SAO & NAO & NPO \\
\hline \multirow[t]{3}{*}{ DRM $_{\text {SODA }}$ vs. POLDER } & Slope & $0.89 \pm 0.004$ & $0.81 \pm 0.009$ & $0.76 \pm 0.01$ \\
\hline & Intercept & $-0.03 \pm 0.001$ & $-0.09 \pm 0.004$ & $-0.03 \pm 0.003$ \\
\hline & $R^{2}(\mathrm{COD})$ & 0.83 & 0.82 & 0.37 \\
\hline \multirow[t]{3}{*}{$\mathrm{DRM}_{\mathrm{Hu}}$ vs. POLDER } & Slope & $0.90 \pm 0.004$ & $0.86 \pm 0.01$ & $0.76 \pm 0.01$ \\
\hline & Intercept & $0.05 \pm 0.001$ & $0.04 \pm 0.004$ & $0.13 \pm 0.003$ \\
\hline & $R^{2}(\mathrm{COD})$ & 0.82 & 0.82 & 0.44 \\
\hline \multirow[t]{3}{*}{ CALIOP $_{\text {OM vs. POLDER }}$} & Slope & $0.34 \pm 0.004$ & $0.52 \pm 0.02$ & $0.28 \pm 0.02$ \\
\hline & Intercept & $-0.04 \pm 0.002$ & $-0.01 \pm 0.01$ & $0.01 \pm 0.01$ \\
\hline & $R^{2}(\mathrm{COD})$ & 0.43 & 0.42 & 0.24 \\
\hline \multirow[t]{3}{*}{ CALIOP $_{\text {OM }}$ vs. DRM SODA $_{\text {S }}$} & Slope & $0.34 \pm 0.002$ & $0.62 \pm 0.01$ & $0.35 \pm 0.01$ \\
\hline & Intercept & $-0.01 \pm 0.002$ & $0.04 \pm 0.006$ & $0.01 \pm 0.007$ \\
\hline & $R^{2}(\mathrm{COD})$ & 0.42 & 0.48 & 0.28 \\
\hline
\end{tabular}



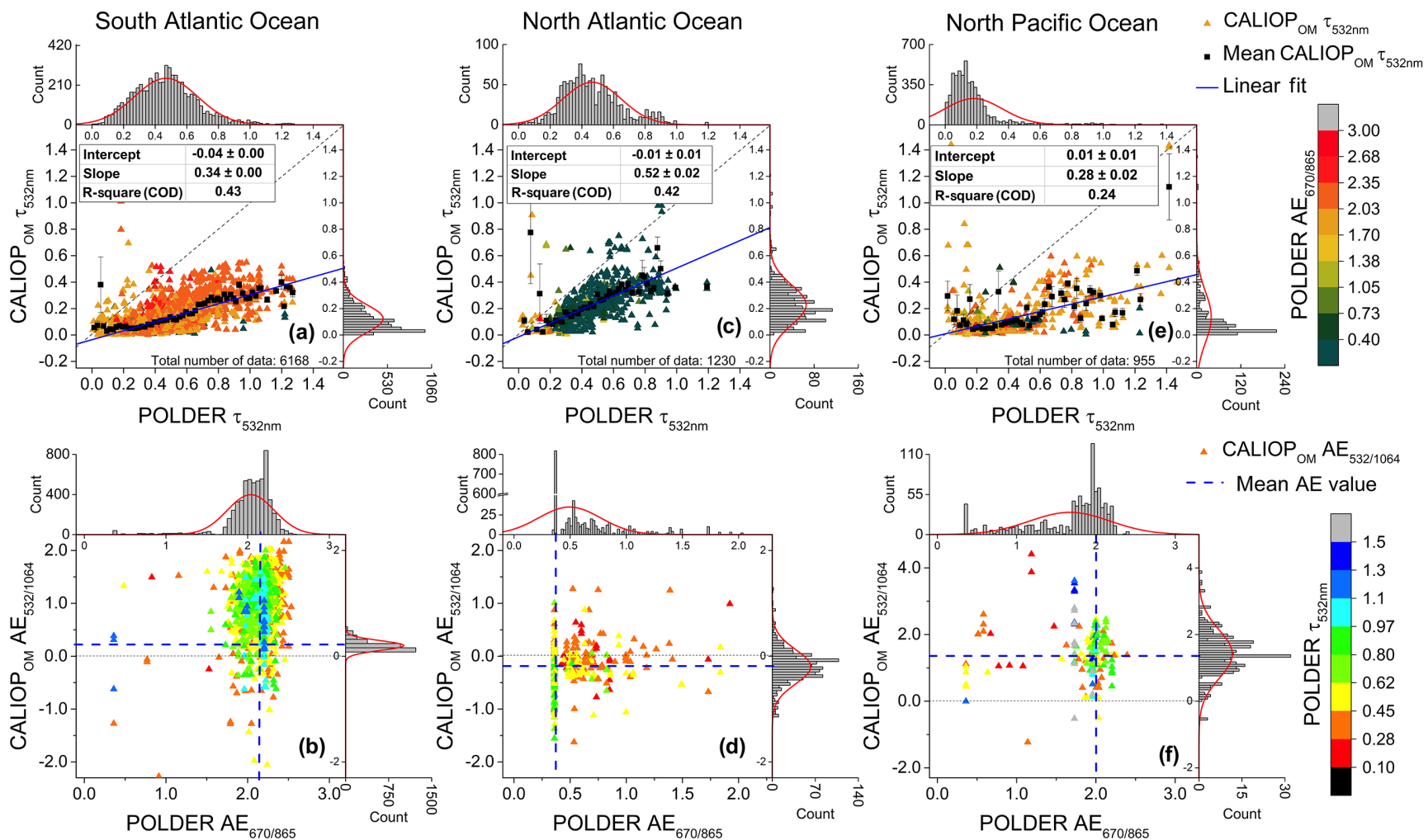

Figure 4. Same as Fig. 3, retrieved from CALIOP operational method and POLDER method.

than 1.8 (Fig. 1d), which is characteristic of fine-mode particles (Dubovik et al., 2002). The DRM $\mathrm{DSDA}_{\text {SOA }} \mathrm{AE}_{532 / 1064}$ is consistent with the POLDER AE, with values higher than 1.5. AOT values retrieved by $\mathrm{CALIOP}_{\mathrm{OM}}$ are much lower than the ones retrieved by the three other techniques. The maximal AOT retrieved by CALIOP OM $_{\text {at }} 532 \mathrm{~nm}$ is 0.5 . A possible explanation for this potential low bias was proposed by Jethva et al. (2014): in case of optically thick aerosol layer, the sensitivity of the backscattered signal to the altitude of the base of the aerosol layer would be reduced or lost, being strongly attenuated by the two-way transmission term. As a result, the operational algorithm may overestimate the aerosol base altitude and so underestimate the geometrical thickness of the aerosol layer and consequently the AOT. The selection of an inappropriate aerosol model (i.e. aerosol lidar ratio $S_{\mathrm{a}}$ for biomass burning varies between $70 \pm 28$ at $532 \mathrm{~nm}$ and $40 \pm 24 \mathrm{sr}$ at $1064 \mathrm{~nm}$; Cattrall et al., 2005; Omar et al., 2005) or the significant biases found in the V3.01 CALIOP $1064 \mathrm{~nm}$ calibration might also contribute to the underestimation of the AOT for this case study. The CALIOP $_{\mathrm{OM}}$ mean $\mathrm{AE}_{532 / 1064}$ seems quite low for fine-mode particles (AE values are lower than 1). The selection of an inappropriate aerosol model might also contribute to the underestimation of the AOT for this case study.

Regional analysis shows that South Atlantic region is mostly characterized by biomass-burning aerosols with large
AOT and AE (Fig. 3a and b). On average, the cloud top height is located below $1.5 \mathrm{~km}$, while the aerosol layers are frequently located between 2.5 and $4 \mathrm{~km}$ (see Table 3 ). The AOT $_{532 \mathrm{~nm}}$ measured by DRM SODA $_{\text {and POLDER may }}$ reach values as large as 1.30 (Fig. 3a), with $80 \%$ of the retrieved AOTs ranging between 0.05 and 0.8 . This AOT intercomparison shows close correlation between DRM SODA and POLDER $\left(R^{2}=0.83\right)$. The mean value of POLDER $\mathrm{AE}_{670 / 865}$ is 2.05, whereas the mean DRM $\mathrm{DODA}_{\text {AE }} \mathrm{AE}_{532 / 1064}$ is 1.79 (Table 5) (both typical for BBA). $\mathrm{DRM}_{\mathrm{Hu}}$ and $\mathrm{DRM}_{\text {SODA }}$ give rather same results. From the linear regressions performed (see Table 2) we can observe that the offset is always positive for $\mathrm{DRM}_{\mathrm{Hu}}$ and systematically larger than the absolute value for DRM SODA $_{\text {when compared to }}$ POLDER method. The AOT estimated by POLDER is constantly between DRM $\mathrm{Hu}_{\mathrm{Hu}}$ and DRM $\mathrm{M}_{\text {SODA }}$.

We do not find a good correlation between the CALIOP ${ }_{\mathrm{OM}}$ and POLDER AOT and AE retrievals. The CALIOP $\mathrm{OM}_{\text {mean }}$ $\mathrm{AOT}_{532 \mathrm{~nm}}$ is 0.12 and the mean $\mathrm{AE}_{532 / 1064}$ is 0.97 . Comparing with POLDER and DRM ${ }_{S O D A}$, CALIOP $_{\mathrm{OM}}$ is underestimating the ACAOT by a factor of 2.92 .

\subsection{Saharan dust aerosols}

For the mineral dust case (Fig. 1e), the cloud top altitude is located at approximately $1 \mathrm{~km}$ altitude whereas the aerosol layer is located between 2 and $5 \mathrm{~km}$ for latitudes be- 
tween 18 and $23^{\circ} \mathrm{N}$. Figure $1 \mathrm{~g}$ shows that the POLDER, $\mathrm{DRM}_{\mathrm{SODA}}$ and $\mathrm{DRM}_{\mathrm{Hu}} \mathrm{AOT}_{532 \mathrm{~nm}}$ increase up to 0.92 , following the same gradient. The correlation coefficients between POLDER parameters and DRM $\mathrm{Hu}_{\mathrm{Hu}}$ and DRM $\mathrm{MODA}_{\mathrm{S}}$ parameters are close (Table 1). The majority of POLDER $\mathrm{AE}_{670 / 865}$ and $\mathrm{DRM}_{\mathrm{SODA}} \mathrm{AE}_{532 / 1064}$ is associated with values lower than 0.4 (Fig. 1h), which indicates that coarsemode particles are predominant (Dubovik et al., 2002). Except for few retrievals associated with an abrupt change in the $\mathrm{AE}$ and AOT measured by CALIOP $\mathrm{OM}$ (around $21^{\circ} \mathrm{N}$ in latitude), $90 \%$ of the CALIOP OM $_{\text {AOT }} \mathrm{AO}_{52 \mathrm{~nm}}$ is lower than 0.45 , being once again underestimated with respect to the other estimates. Most of CALIOP $\mathrm{OM}_{\mathrm{OM}} \mathrm{AE}_{532 / 1064}$ values are underestimated (i.e. overestimation of the particles size) in comparison with the AE retrieved by the two other algorithms. These low values of AOT and AE may be explained once more by a biased CALIOP calibration at $1064 \mathrm{~nm}$ combined with an unfitted model selection (i.e. for desert dust, $S_{\mathrm{a}}$ is equal to $40 \pm 20 \mathrm{sr}$ at $532 \mathrm{~nm}$ and $55 \pm 17 \mathrm{sr}$ at $1064 \mathrm{~nm}$; Cattrall et al., 2005; Omar et al., 2005).

A regional study shows similar AOT and AE results over the North Atlantic region (Fig. 3c). On average, the aerosol layers are located between 3 and $4.5 \mathrm{~km}$ and the cloud top heights are typically around $1.4 \mathrm{~km}$ (see Table 3 ). The values of $\mathrm{AOT}_{532}$ retrieved from POLDER and DRM SODA $_{\text {are }}$ well correlated $\left(R^{2}=0.82\right)$, with maximum values of, respectively, 1.19 and 0.95 . Nonetheless, we observe a larger offset between DRM SODA $_{\text {and POLDER AOT }}{ }_{532 \mathrm{~nm}}$ for this region (-0.09) compared to the South Atlantic Ocean region $(-0.03)$. The use of only one dust model in the LUT algorithm used for POLDER remains a limitation that might explain this larger offset. The introduction of additional dust models with larger or smaller effective radius values may contribute to improve the AOT retrievals for dust AAC events. Regarding the POLDER $\mathrm{AE}_{670 / 865}$ retrievals, most of the values are lower than 0.4 , which is expected for desert dust aerosols (Fig. 3c and d). However, for AOT values lower than 0.2 , the $\mathrm{AE}_{670 / 865}$ retrieved by POLDER is between 1.4 and 2.2. This is explained by the fact that the selection of the dust model is not permitted in the POLDER algorithm in case of low AOTs. Nonetheless, all three methods are consistent in revealing the predominance of the coarse mode. The mean values for the AE are 0.49 for POLDER, 0.10 for DRM SODA and -0.19 for CALIOPOM. The AOT $_{532 \mathrm{~nm}}$ correlation between CALIOP ${ }_{\mathrm{OM}}$ and POLDER is low, with $R^{2}=0.42$.

\subsection{East Asian mixture of aerosols}

The CALIOP transect shows that Siberian biomass-burning case is located between 40 and $52^{\circ} \mathrm{N}$, the cloud top altitude is constantly around $1 \mathrm{~km}$ and the base of the aerosol layer decreases from $10 \mathrm{~km}$ in the south (at $45^{\circ} \mathrm{N}$ ) to around $2 \mathrm{~km}$ in the north $\left(\right.$ at $\left.54^{\circ} \mathrm{N}\right)$ (Fig. 1i). We notice also cirrus clouds at high altitude (around $10 \mathrm{~km}$ ) between 47 and $51^{\circ} \mathrm{N}$, which were efficiently eliminated from the retrievals (Fig. 1k). The
Table 3. Regional analysis using CALIOP measurements over 6 months (May to October 2008), over South Atlantic Ocean (SAO), North Atlantic Ocean (NAO) and North Pacific Ocean (NPO): mean cloud altitude for altitudes smaller than $5 \mathrm{~km}$, mean aerosol base and top altitudes for altitudes smaller than $10 \mathrm{~km}$.

\begin{tabular}{|c|c|c|c|}
\hline & $\mathrm{SAO}$ & NAO & NPO \\
\hline $\begin{array}{l}\text { Mean cloud top } \\
\text { altitude }(\mathrm{km})\end{array}$ & $\begin{array}{l}1.24 \pm 0.43 \\
\text { Min: } 0.30 \\
\text { Max: } 4.95\end{array}$ & $\begin{array}{l}1.35 \pm 0.5 \\
\text { Min: } 0.20 \\
\text { Max: } 3.25\end{array}$ & $\begin{array}{l}1.09 \pm 0.84 \\
\text { Min: } 0.05 \\
\text { Max: } 5.0\end{array}$ \\
\hline $\begin{array}{l}\text { Mean aerosol top } \\
\text { altitude }(\mathrm{km})\end{array}$ & $\begin{array}{l}3.83 \pm 0.093 \\
\text { Min: } 0.50 \\
\operatorname{Max}: 6.73\end{array}$ & $\begin{array}{l}4.50 \pm 1.03 \\
\text { Min: } 0.44 \\
\text { Max: } 6.67\end{array}$ & $\begin{array}{l}2.74 \pm 1.68 \\
\text { Min: } 0.47 \\
\text { Max: } 9.85\end{array}$ \\
\hline $\begin{array}{l}\text { Mean aerosol base } \\
\text { altitude }(\mathrm{km})\end{array}$ & $\begin{array}{l}2.90 \pm 0.97 \\
\text { Min: } 0.02 \\
\text { Max: } 5.80\end{array}$ & $\begin{array}{l}2.97 \pm 1.12 \\
\text { Min: } 0.02 \\
\text { Max: } 5.74\end{array}$ & $\begin{array}{l}3.48 \pm 1.78 \\
\text { Min: } 0.05 \\
\text { Max: } 9.31\end{array}$ \\
\hline
\end{tabular}

Table 4. Calculated mean, minimum value and maximum value of AOT $_{532 \mathrm{~nm}}$ over 6 months in 2008, for three regions (SAO, NAO, NPO) and for different methods.

\begin{tabular}{llrrr}
\hline AOT $_{532 \mathrm{~nm}}$ & & $\mathrm{SAO}$ & $\mathrm{NAO}$ & $\mathrm{NPO}$ \\
\hline POLDER & Mean & $0.35 \pm 0.23$ & $0.39 \pm 0.21$ & $0.18 \pm 0.21$ \\
& Min & 0.005 & 0.005 & 0.005 \\
& Max & 1.27 & 1.19 & 2.17 \\
\hline \multirow{2}{*}{ DRM $_{\text {SODA }}$} & Mean & $0.28 \pm 0.22$ & $0.23 \pm 0.19$ & $0.15 \pm 0.38$ \\
& Min & -0.13 & -0.16 & -0.16 \\
& Max & 1.30 & 0.95 & 3.26 \\
\hline DRM $_{\text {Hu }}$ & Mean & $0.37 \pm 0.23$ & $0.38 \pm 0.20$ & $0.32 \pm 0.40$ \\
& Min & -0.07 & -0.06 & -0.06 \\
& Max & 1.50 & 1.17 & 3.68 \\
\hline CALIOP $_{\text {OM }}$ & Mean & $0.12 \pm 0.11$ & $0.23 \pm 0.18$ & $0.14 \pm 0.23$ \\
& Min & 0.001 & 0.005 & 0.001 \\
& Max & 1.88 & 2.38 & 2.01 \\
\hline & & & &
\end{tabular}

maximum POLDER AOT value is as large as 1.9 , while DRM reaches 1.3 in AOT. Nonetheless, Table 1 shows that POLDER and DRM methods AOT $_{532 \mathrm{~nm}}$ retrievals are consistent $\left(R^{2}=0.90\right)$. POLDER $\mathrm{AE}_{670 / 865}$ values are between 1.7 and 2.3, indicating small particles of smoke, while DRM $_{\text {SODA }} \mathrm{AE}_{532 / 1064}$ has a large range of values (Fig. 11). The number of sampled ACAOT events by CALIOP $_{O M}$ is

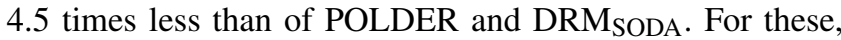
the CALIOP OM AOTs are underestimated by a factor of 1.5 compared to ones retrieved by the other methods. Also, the correlation coefficient with POLDER is 0.45 .

On a regional scale, this area is under the influence of various aerosols (BBA, DDA, pollution) and elevated cirrus clouds are frequent. The mean cloud top altitude is around $1 \mathrm{~km}$ and the aerosols are between $2.5 \mathrm{~km}$ and $4.0 \mathrm{~km}$. As indicated in Table 3, the maximum aerosol altitude is $9.85 \mathrm{~km}$, which might suggests cirrus misclassification. In some cases, 

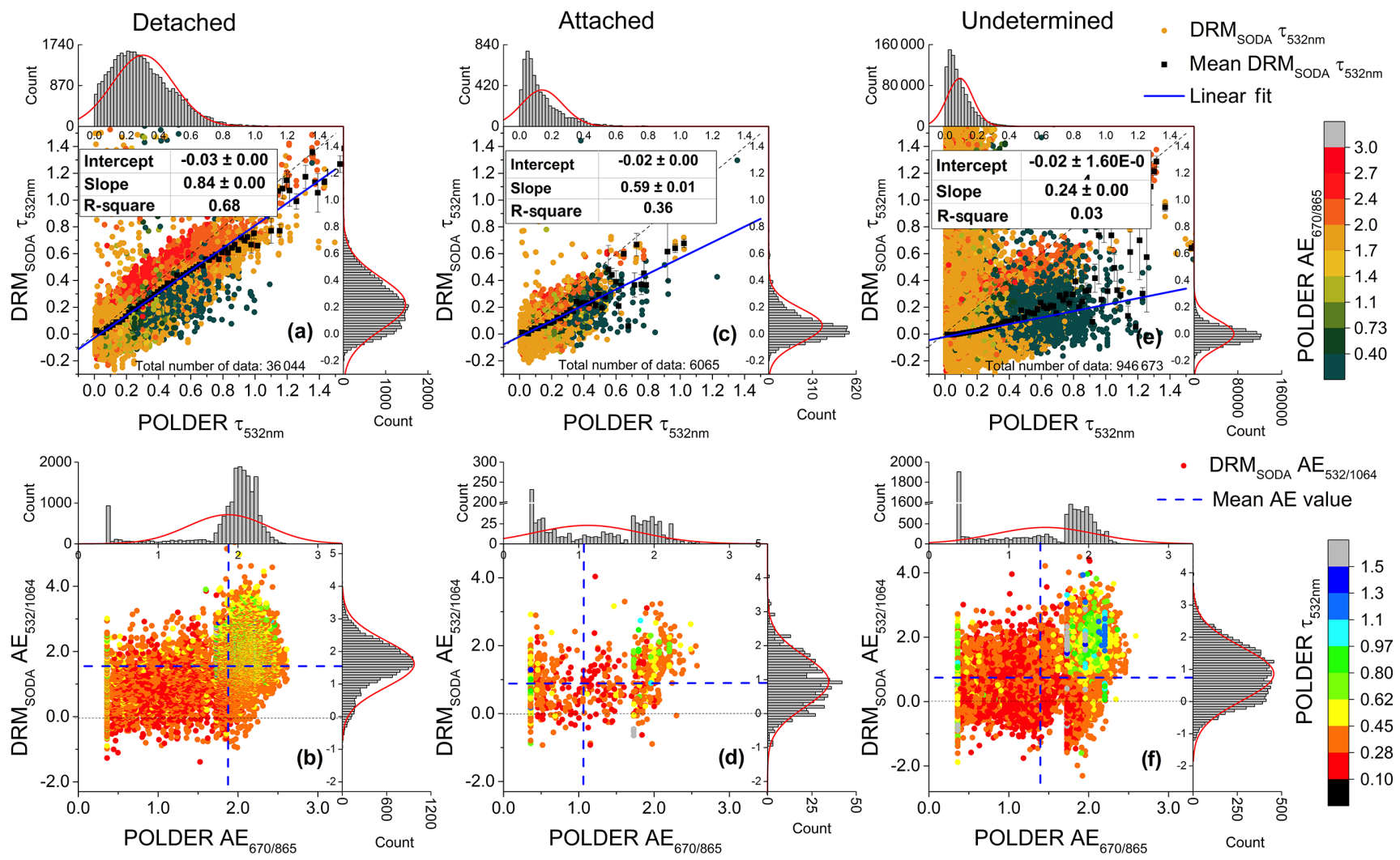

Figure 5. Global comparison over a period of 4.5 years (June 2006-December 2010) for situations with aerosol layer well separated from the cloud top ("detached"; a, b), for cases where the aerosol layer is in contact with the cloud ("attached"; c, d) and for "undetermined"

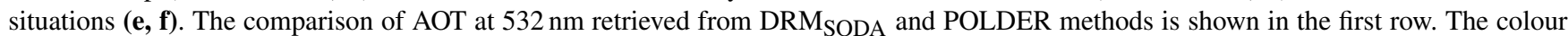
scale represents the corresponding POLDER AE computed between 670 and $865 \mathrm{~nm}$. The second row presents the Ångström exponent for AOTs larger than 0.1, with a POLDER AOT at $532 \mathrm{~nm}$ colour scale. The histograms present the data distribution. The error bars in (a), (c) and (e) represent the standard error of the mean (SEM).

DRM $_{\text {SODA }}$ gives large values of AOT $_{532 \mathrm{~nm}}$ (larger than 1) whereas the POLDER estimates AOT $532 \mathrm{~nm}$ smaller than 0.2. These situations could be explained by a misinterpretation of thin cirrus clouds as aerosols. Otherwise, the POLDER mean $\mathrm{AOT}_{532 \mathrm{~nm}}$ and DRM SODA $\mathrm{AOT}_{532 \mathrm{~nm}}$ are in rather close agreement ( 0.18 and 0.15 , respectively; see Table 4$)$, but the correlation between them is low $\left(R^{2}=0.37\right.$, Table 2$)$. All methods show a large variability for the retrieved AE, with values that correspond to particle size distributions dominated by coarse or fine modes and mixtures (Table 5). As previously mentioned, the algorithm developed for POLDER uses a bimodal aerosol model for dust. However, the possibility of mixing different fine and coarse aerosol models in various proportions is not yet included. This might explain why we found a lower correlation between the POLDER and DRM retrievals for this region. As for above, the CALIOP $\mathrm{OM}$ and POLDER AOT $532 \mathrm{~nm}$ are not correlated $\left(R^{2}=0.24\right)$.

In general, there is a good agreement between POLDER

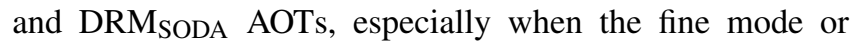
coarse mode dominates the particle size distribution (i.e. BBA and DDA). Overall, DRM ${ }_{\text {SODA }}$ and $\mathrm{DRM}_{\mathrm{Hu}}$ give sim- ilar results. However, the AOTs retrieved with $\mathrm{DRM}_{\mathrm{Hu}}$ are generally larger than those of DRM SODA $_{\text {for all the three }}$ regions (i.e. 0.37 compared to 0.28 for SAO; see Table 4).

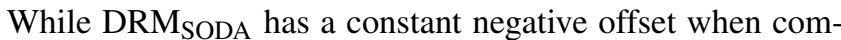
pared to POLDER, DRM $\mathrm{Hu}_{\mathrm{u}}$ rarely retrieves null AOT values (offsets always larger than 0; see Table 2). This is likely to be a consequence of the calibration performed for the DRM SODA method. Also, there is no obvious correlation between the CALIOP ${ }_{O M}$ and POLDER AOT $_{532 \mathrm{~nm}}$ retrievals for all regions.

Finally, in addition to the 6-month regional study, we also examined the impact of the vertical aerosol-cloud profiles over the three regions using data acquired from May to October between 2006 and 2010. We systematically found higher correlation coefficients between the DRM $M_{\text {SODA }}$ and POLDER AOTs when the layers were well separated than when they were in contact (see Table 6). These results have led us to consider the vertical distribution of aerosols and clouds in the global comparison. 
Table 5. Mean value of AE over 6 months in 2008 for three regions (SAO, NAO, NPO) for different methods after filtering the POLDER $\mathrm{AOT}_{865 \mathrm{~nm}}>0.1$ and DRM SODA $\mathrm{AOT}_{532 \mathrm{~nm}}>0.1$ and the CALIOP $\mathrm{OM} \mathrm{AOT}_{532 \mathrm{~nm}}>0.1$.

\begin{tabular}{llrrr}
\hline & & SAO & NAO & NPO \\
\hline \multirow{2}{*}{ POLDER } & Mean AE $670 / 865$ & $2.05 \pm 0.27$ & $0.49 \pm 0.27$ & $1.67 \pm 0.50$ \\
& Min & 0.36 & 0.36 & 0.36 \\
& Max & 2.56 & 2.03 & 2.39 \\
\hline \multirow{2}{*}{ DRM $_{\text {SODA }}$} & Mean AE & & \\
& Min & $1.79 \pm 0.58$ & $0.10 \pm 0.27$ & $1.47 \pm 0.84$ \\
& Max & -1.15 & -1.14 & -1.21 \\
CALIOP $_{\text {OM }}$ & Mean $\mathrm{AE}_{532 / 1064}$ & $0.97 \pm 0.51$ & $-0.19 \pm 0.32$ & $0.41 \pm 0.72$ \\
& Min & -2.27 & -1.62 & -2.63 \\
& Max & 3.16 & 1.27 & 4.41 \\
\hline
\end{tabular}

Table 6. Linear regression calculated between DRM SODA $_{\text {AOT }} 532 \mathrm{~nm}$ and POLDER AOT $_{532 \mathrm{~nm}}$ for situations when the aerosol layer is attached to the cloud top and when the aerosol layer is well separated from the cloud over three regions (South Atlantic Ocean, North Atlantic Ocean and North Pacific Ocean) and for a period of 4.5 years.

\begin{tabular}{lrr|rr|rr}
\hline & \multicolumn{2}{c}{ SAO } & \multicolumn{2}{c|}{ NAO } & \multicolumn{2}{c}{ NPO } \\
\cline { 2 - 6 } & Attached & Detached & Attached & Detached & Attached & Detached \\
\hline Slope & $0.60 \pm 0.02$ & $0.77 \pm 0.003$ & $0.63 \pm 0.07$ & $0.59 \pm 0.01$ & $0.78 \pm 0.12$ & $0.80 \pm 0.02$ \\
Intercept & $0.04 \pm 0.006$ & $0.02 \pm 0.001$ & $-0.005 \pm 0.02$ & $-0.011 \pm 0.006$ & $-0.04 \pm 0.02$ & $-0.015 \pm 0.007$ \\
$R^{2}(\mathrm{COD})$ & 0.54 & 0.715 & 0.39 & 0.57 & 0.19 & 0.435 \\
\hline
\end{tabular}

\section{Global analysis on different types of scenes}

\subsection{Detached, attached, undetermined}

Figure 5a shows the global comparison between the $\mathrm{AOT}_{532 \mathrm{~nm}}$ and AE retrieved with POLDER and DRM for the detached cases. The AE comparison was only performed when the POLDER AOT at $865 \mathrm{~nm}$ and DRM SODA AOT at $532 \mathrm{~nm}$ are larger than 0.1 . The colour scales used in Fig. 5 represent either the POLDER $\mathrm{AE}_{670 / 865}$ for the AOT comparison (Fig. 5a) or the POLDER AOT $532 \mathrm{~nm}$ for the AE comparison (Fig. 5d). Considering the large amount of selected data ( $85.6 \%$ of the two-layer cases) in terms of both spatial and temporal coverage, the comparison shows a good correlation between the two methods $\left(R^{2}=0.68\right)$. A better agreement between the methods is found when the values

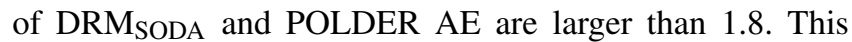
is likely due to the fact that the POLDER method is more sensitive to fine-mode aerosols, due to polarization measurements, and also because an improved description of the finemode properties was included in the LUT (i.e. six fine-mode aerosol models are used).

Events for which the aerosol layer is attached to the cloud top represent $14.4 \%$ of the total number of two-layer cases. They are associated with lower AOT and the correlation between the two retrievals largely decreases (compared to the detached events). The correlation between the two AOT retrievals also decreases $\left(R^{2}=0.36\right.$, Fig. $\left.5 \mathrm{c}\right)$. The POLDER
AOT is larger by a coefficient of 1.7 than the DRM AOT on average. The AE given by both methods is approximately 1.0 (when considering only $\mathrm{AE}$ values associated with AOT $>0.1$ ). The lateral histogram shows that the POLDER method identifies AAC events associated with both low and high $\mathrm{AE}$ values, resulting in a mean $\mathrm{AE}$ of about 1.0.

The undetermined situations correspond to retrievals when CALIOP does not give all the information regarding the layer altitudes. The number of cases is significant (approximately $92 \%$ of the total number of global retrievals) but most of data $(95 \%)$ correspond to $\mathrm{AOT}_{532 \mathrm{~nm}}$ lower than 0.2. This probably explains why the layer detection algorithm has difficulties in estimating the base and top of the aerosol layer. For the undetermined cases, we observe that there is not

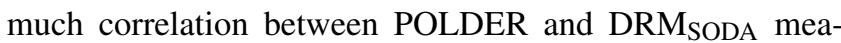

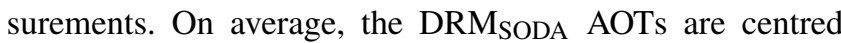
around zero for this category whereas POLDER has a nonnegligibly low AOT for most cases. In this category, the AE comparison shows a better consistency between the methods for $\mathrm{AOT}_{532 \mathrm{~nm}}>0.5$ and for AE of approximately 2.0.

Table 7 shows the results of the linear regressions performed between the AOTs retrieved with POLDER and the other active methods considered in our study for each category (i.e. detached, attached and undetermined). We recapture the systematically larger offsets of DRM $\mathrm{Hu}_{\mathrm{H}}$ $\mathrm{AOT}_{532 \mathrm{~nm}}$ compared to DRM $\mathrm{SODA}_{\text {and the underestimation }}$ of CALIOP ${ }_{\mathrm{OM}}$ AOT with respect to the other methods. 
Table 7. Linear regressions calculated between different methods for data acquired over June 2006 to December 2010, on a global scale above the ocean in the case of aerosol attached to the cloud top, detached from the cloud and undetermined situations for AOT smaller than 1.5 .

\begin{tabular}{llrrr}
\hline Linear regressions & & Detached & Attached & Undetermined \\
\hline DRM $_{\text {SODA vs. POLDER }}$ & Slope & $0.84 \pm 0.003$ & $0.59 \pm 0.01$ & $0.24 \pm 0.001$ \\
& Intercept & $-0.03 \pm 0.001$ & $-0.02 \pm 0.002$ & -0.02 \\
& $R^{2}(\mathrm{COD})$ & 0.68 & 0.36 & 0.03 \\
\hline DRM $_{\text {Hu }}$ vs. POLDER & Slope & $0.78 \pm 0.002$ & $0.55 \pm 0.001$ & $0.28 \pm 0.001$ \\
& Intercept & $0.10 \pm 0.001$ & $0.12 \pm 0.002$ & 0.09 \\
& $R^{2}$ (COD) & 0.68 & 0.36 & 0.05 \\
\hline CALIOP $_{\text {OM vs. POLDER }}$ & Slope & $0.17 \pm 0.002$ & $0.12 \pm 0.007$ & $0.06 \pm 0.008$ \\
& Intercept & 0.013 & $0.02 \pm 0.001$ & $0.14 \pm 0.002$ \\
& $R^{2}$ (COD) & 0.15 & 0.047 & 0.003 \\
\hline CALIOP $_{\text {OM vs. DRM }}$ SODA & Slope & $0.17 \pm 0.002$ & $0.1 \pm 0.007$ & $0.21 \pm 0.01$ \\
& Intercept & 0.029 & $0.04 \pm 0.001$ & $0.14 \pm 0.001$ \\
& $R^{2}$ (COD) & 0.15 & 0.03 & 0.01 \\
\hline
\end{tabular}

\subsection{Evolution of the above-cloud AOT retrievals with cloud properties}

In principle, the retrieval of AAC properties from the methods considered in this study should not depend on the properties of the underlying clouds. However, hypotheses and empirical relations used in the retrieval methods to exploit the signal backscattered by the underlying cloud cover obviously have their limitations. In order to understand potential issues linked with diversity of cloud properties, we analyse in this section the difference between the AOT retrievals of POLDER, DRM ${ }_{S O D A}$ and DRM $\mathrm{Du}_{\mathrm{Hu}}$ by classes of cloud properties (COT and $r_{\text {eff }}$ retrieved with MODIS). We considered global measurements acquired for 4.5 years of data and used the classification defined in Sect. 2.3.2.

Figure 6 presents POLDER and DRM trievals as a function of the MODIS droplets effective radius $\left(r_{\text {eff }}\right)$, while Fig. 8 displays POLDER and DRM $\mathrm{AOT}_{532 \mathrm{~nm}}$ as a function of the MODIS COT. Histograms of the cloud properties are also reported in Figs. 6, 7 and 8. The results of the POLDER and $\mathrm{DRM}_{\mathrm{Hu}} \mathrm{AOT}_{532}$ comparison as a function of the effective radius are shown in Fig. 7. $\mathrm{DRM}_{\mathrm{SODA}}$ and $\mathrm{DRM}_{\mathrm{Hu}} \mathrm{AOT}_{532 \mathrm{~nm}}$ generally exhibit rather similar behaviour, at least qualitatively. Therefore, we did not report the results found for the $\mathrm{DRM}_{\mathrm{Hu}} \mathrm{AOT}_{532}$ as a function of MODIS COT.

\subsubsection{AOT vs. $r_{\text {eff }}$}

The lateral histograms plotted in Figs. 6 and 8 show that most of the AAC scenes correspond to cloud droplets effective radius values between 8 and $15 \mu \mathrm{m}$ (mean $r_{\text {eff }}$ equal to $12 \mu \mathrm{m}$ ) and COT ranging from 5 to 15 (mean COT of 10). These mean values are expected since most of the of AAC events are generally associated with low-level non- precipitating clouds, such as stratocumulus ones, which typically show rather small droplets (approximately $10 \mu \mathrm{m}$ ) and optical thickness values of approximately 10 .

Figure 6a shows the POLDER and DRM SODA $_{\text {AOTs for }}$ the detached situations. For the two methods, the retrieved AOTs are maximal for the smallest values of $r_{\mathrm{eff}}$ and progressively decrease with $r_{\text {eff. }}$. Same tendencies are observed for the DRM $\mathrm{Hu}_{\mathrm{Hu}}$ (see Fig. 7a). The two curves have an offset, however. The histogram of the differences between POLDER and DRM $\mathrm{DODA}_{\mathrm{SOT}}$ AO $(\Delta \tau)$ is presented in Fig. $6 \mathrm{~d}$. The mean $\Delta \tau$ value computed over the entire range of $r_{\text {eff }}$ is equal to 0.073 . This offset is not constant and slightly increases with $r_{\text {eff }}$, suggesting a sensitivity of one of the two methods to the cloud droplets effective radius. The DRM algorithm does not use an explicit parameterization of the lidar ratio as a function of the cloud droplets effective radius. An implicit dependence will arise from the latitudinal correction (Eq. 9) when clouds at different latitudes exhibit different microphysical properties. In order to understand the usefulness of adding an explicit parameterization, we recalculated the DRM $\mathrm{SODA}$ AOT $_{532 \mathrm{~nm}}$, taking into account the dependence of $S_{\mathrm{c}}$ on $r_{\mathrm{eff}}$. This calculation assumes a simplified and unique droplet size distribution and is based on MODIS $r_{\text {eff }}$ retrieval. We expect that even if the cloud droplet size distribution is variable (Miles et al., 2000) and the ACAOT creates a bias in $r_{\text {eff }}$, the results will still provide guidance for future algorithm development. As defined in Josset et al. (2011), $S_{\mathrm{c}}$ was computed using a Mie code with the following equation:

$S_{\mathrm{c}}=\frac{4 \pi}{\omega_{0} \times p\left(180^{\circ}\right)}$,

where $p\left(180^{\circ}\right)$ is the average value of the phase function in the backscatter direction computed over the size distribution. $\omega_{0}$ is the SSA of the particles, defined as the ratio 


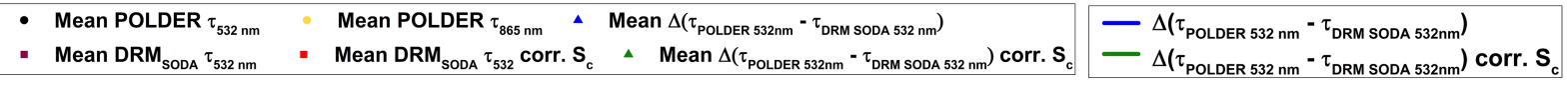
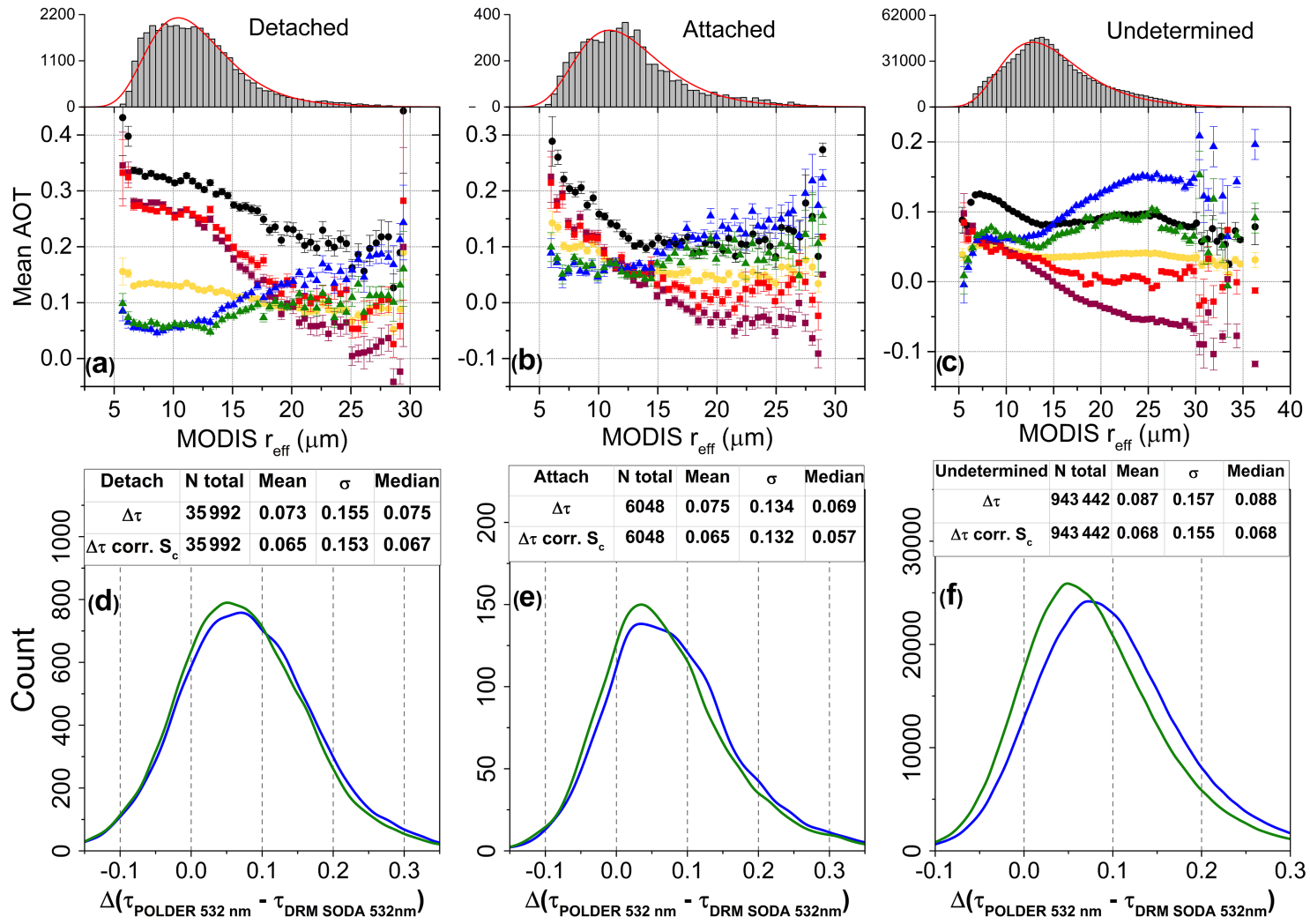

Figure 6. Four and a half years of global study on the evolution of POLDER and DRM $\mathrm{SODA}$ above-cloud AOT retrievals as a function of MODIS effective radius $\left(r_{\text {eff }}, \mu \mathrm{m}\right)$ for situations where the aerosol layer is detached from the cloud top (a, d), for cases where the aerosol layer is attached to the cloud top (b, e) and for undetermined situations (c, f). The histograms in (a)-(c) represent the distribution of $r_{\text {eff }}$. The histograms in (d)-(f) present the difference between POLDER and DRMSODA mean AOTs, before the correction of DRM with $r_{\text {eff }}(\Delta \tau)$ and after this correction $\left(\Delta \tau\right.$ corr. $\left.S_{\mathrm{c}}\right)$. The associated tables indicate the number of cases, mean, standard deviation $(\sigma)$ and median values of these differences. The error bars in (a)-(c) represent the standard error of the mean (SEM).

between the mean scattering coefficient and the mean extinction coefficient computed over the particle size distribution. We used a two-parameter gamma size distribution with an effective variance of 0.088 . The real refractive index was set to 1.337. Liquid water droplets do not significantly absorb at $532 \mathrm{~nm}$ and the imaginary part of the complex refractive index was set to 0 . As shown in Fig. 9, $S_{\mathrm{c}}$ slightly decreases with $r_{\text {eff }}$ from 19.5 to 15.5 as the effective radius values increases from 5 to $40 \mu \mathrm{m}$. With this correction, the mean difference between POLDER and the DRM SODA $_{\text {AOT }}$ S32 $_{2 m}$ $\left(\Delta \tau \operatorname{corr} S_{\mathrm{c}}\right.$ in Fig. 6d) decreases from 0.073 to 0.065 . We found equivalent results for the attached and undetermined cases (Fig. 6b and c). After correction of $S_{\mathrm{c}}$, the difference between POLDER and DRM ${ }_{\text {SODA }}$ decreases on average by 0.01 for the attached cases and by 0.019 for the undetermined cases. We also observe that most of the negative AOT values retrieved by the DRM SODA $_{\text {shift either to null values }}$ or weakly positive values when this correction is included
(Fig. 6a-c). We are aware that MODIS effective radius may be affected by the presence of aerosols above clouds. For example, Haywood et al. (2004) found biases of $\pm 2 \mu \mathrm{m}$ for $r_{\text {eff }}$ in case of strong dust events above clouds and Meyer et al. (2015) found an increase in the $r_{\text {eff }}$ monthly mean of $2 \%$ in case of above-cloud absorbing aerosols. We expect that large biases on $r_{\text {eff }}$ could be possible in case of high aerosol loading for detached cases. However, we consider that the impact of the biases on the retrieved $r_{\text {eff }}$ on our findings and conclusions can be neglected, since the analysis hold for (i) a wide range of droplets effective radius (from 5 to $40 \mu \mathrm{m}$ ) and (ii) AAC events associated with low aerosol loadings (see the results for the undetermined cases), where the impacts of the aerosols on the cloud retrievals are expected to be minimized or negligible. 


\begin{tabular}{|c|c|}
\hline 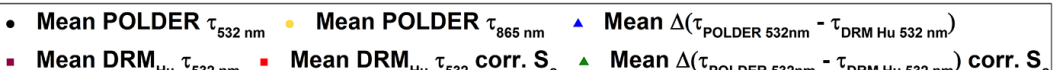 & $\begin{array}{l}-\Delta\left(\tau_{\text {POLDER } 532 \mathrm{~nm}}-\tau_{\text {DRM Hu } 532 \mathrm{~nm}}\right) \\
-\Delta\left(\tau_{\text {POLDER } 532 \mathrm{~nm}}-\tau_{\text {DRM Hu } 532 \mathrm{~nm}}\right) \text { corr. } S_{\text {e }}\end{array}$ \\
\hline
\end{tabular}
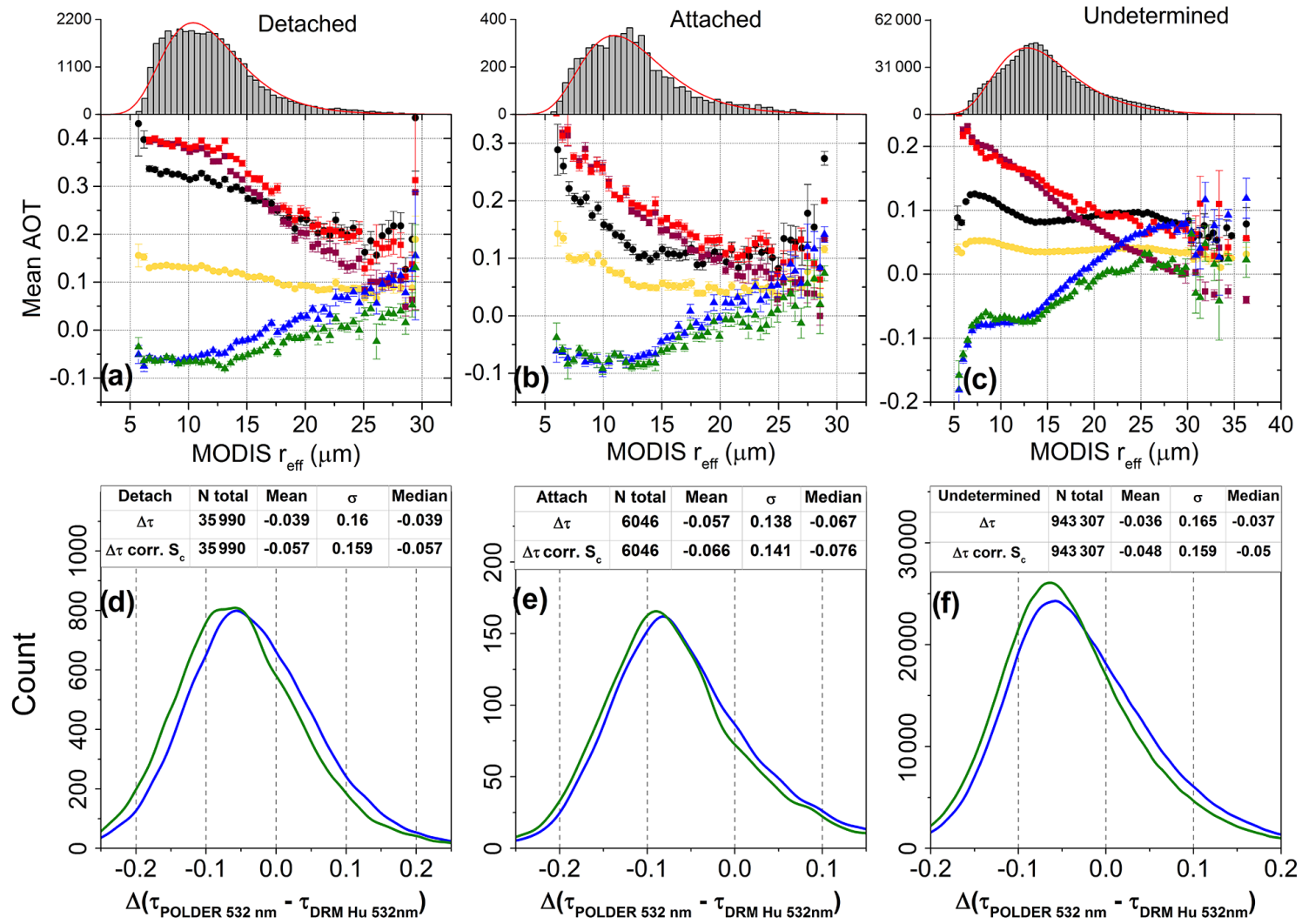

Figure 7. Same as Fig. 6: POLDER and DRM $\mathrm{Hu}_{\mathrm{u}}$ above-cloud AOT retrievals as a function of MODIS effective radius $\left(r_{\mathrm{eff}}, \mu \mathrm{m}\right)$.

\subsubsection{AOT vs. COT}

The two methods were developed to detect AAC events in the case of optically thick and homogeneous liquid water clouds. In the following, we only discuss results obtained for large values of COT (larger than 5). If the clouds are optically thinner, the two methods are potentially less accurate since they become sensitive to the surface contribution. Hu et al. (2007a) noticed the surface impact on DRM $\mathrm{Hu}_{\mathrm{H}}$ when the underlying cloud is not entirely opaque; therefore the assumptions used in the DRM $\mathrm{Hu}_{\mathrm{Hu}}$ AOT retrievals are not met. For COTs ranging between 5 and 30 and for detached cases, the POLDER AOTs are almost constant and reach 0.3 on average at $532 \mathrm{~nm}$ (see Fig. 8a). Most of the associated COT values then range between 5 and 10. For these cases, DRM $_{\text {SODA }}$ and POLDER AOTs are offset by around 0.07 on average, as noted above. However, the DRM progressively increases with the COT, which is not observed for the POLDER AOT. Consequently, the differences in AOT between the two methods become almost negligible for the largest (and less frequent) values of COT (larger than 20). For COTs larger than 3 , the polarized signal reflected by the cloud is saturated and the POLDER method should be in-

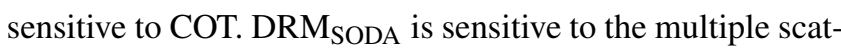
tering processes occurring within the cloud layers and might be impacted by the COT since multiple scattering increases with the optical thickness. The measured depolarization $\left(\delta^{\prime}\right)$ and the multiple scattering factor $\left(\eta_{\text {calibr }}\right)$ plotted as a function of the COT are shown in Fig. 8d. As expected, the depolarization and the multiple scattering factor respectively increase and decrease as COT increases. The increase in the

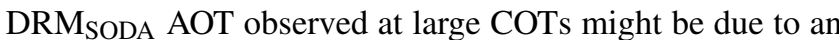
increase in the multiple scattering. We recall that DRM SODA $_{\text {S }}$ uses a relationship to connect the depolarization and the multiple scattering factor and that this relation is calibrated based on CALIOP data. The calibration might be less accurate in the case of AAC events associated with clouds for which the properties are statistically less representative. Again, we presume that our conclusions are not impacted by the fact that the MODIS COTs can be potentially biased in case of AAC events since the tendencies we observed hold for a large range of variability in COT (5 to 30 ) and also for AAC events associated with low AOT above clouds (see the results for the undetermined cases). 

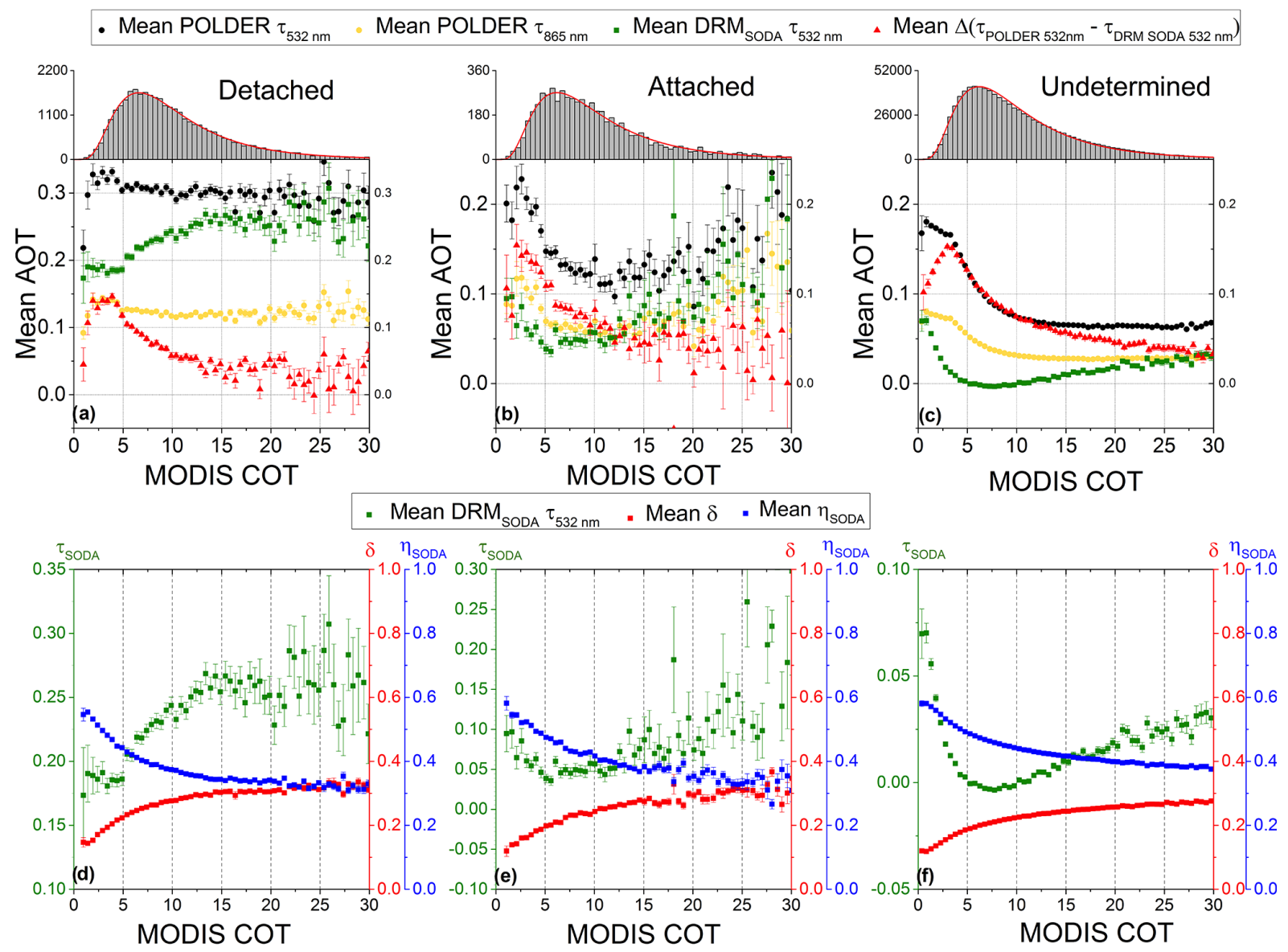

Figure 8. Four and a half years of global study of the evolution of POLDER and DRM $\mathrm{SODA}$ above-cloud AOT retrievals, as well as the difference of these two methods as a function of MODIS cloud optical thickness (COT), for situations where the aerosol layer is detached from the cloud top (a), for cases where the aerosol layer is attached to the cloud top (b) and for undetermined situations (c). The histograms represent the distribution of COT. The error bars show the standard error of the mean (SEM). Panels (d)-(f) display the evolution of DRMSODA AOT $\left(\tau_{\text {SODA }}\right)$, depolarization ratio $(\delta)$ and multiple scattering factor $\left(\eta_{\text {SODA }}\right)$ as a function of MODIS COT, for the abovementioned situations.

\section{Discussion}

In the first part of this section, we quantify and discuss the overall differences found between the active and passive methods in terms of the retrieved AOT. In the second part, we address more specifically the attached cases and make hypotheses regarding the meaning of these results.

On average, the difference between POLDER and DRM $_{\text {SODA }}$ AOTs at $532 \mathrm{~nm}$ is equal to 0.073 for the detached cases and 0.087 for the undetermined cases. These differences slightly decrease to 0.065 and 0.068 , respectively, when we account for the dependency of the cloud droplets lidar ratio $\left(S_{\mathrm{c}}\right)$ to $r_{\text {eff }}$ in Eq. (10). The POLDER AOTs are systematically smaller than the ones retrieved with $\mathrm{DRM}_{\mathrm{Hu}}$. On average, these differences between these two methods are equal to -0.039 and -0.057 , for the detached cases, and reach -0.036 and -0.048 for the undetermined cases, respectively without and with corrections for $S_{\mathrm{c}}$. Thereby, the POLDER AOT estimates range, on average, between the

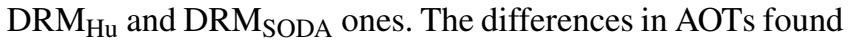
between the POLDER method and the two DRM ones could be set to zero by modifying the lidar calibration by roughly $\pm 10 \%$. One another main difference between the three methods is their different responses in terms of AOT when the atmosphere above the clouds becomes pristine. The majority of AOT (94\%) is lower than 0.1 at $865 \mathrm{~nm}$ for the undetermined cases. For these cases, the POLDER algorithm retrieves a mean AOT of about 0.04 at $865 \mathrm{~nm}$. The accuracy of the POLDER AOT product is on the same order of magnitude. For an $\mathrm{AOT}_{865} \mathrm{~nm}$ of 0.2 , the error for a real refractive index uncertainty of \pm 0.06 would be about 0.05 ; for an imaginary refractive index uncertainty of \pm 0.01 , the error would be of 0.02 (Peers et al., 2015). The impact of the assumed refractive index is lower at smaller AOT (especially for an AOT of 0.04). The background of the extrapolated POLDER AOT at $532 \mathrm{~nm}$ for the undetermined cases reaches 0.09 . This latter value is only reported for the sake of comparison with the two other methods since the Ångström ex- 


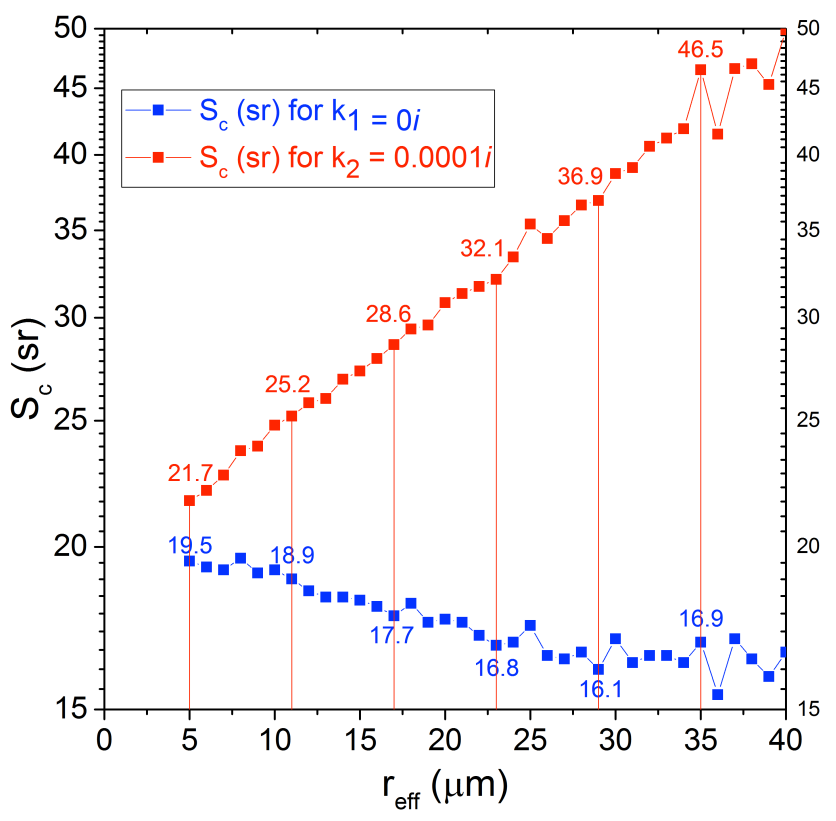

Figure 9. Sensitivity study of lidar ratio $\left(S_{\mathrm{c}}, \mathrm{sr}\right)$ as a function of the cloud droplets effective radius, using a two-parameter gamma size distribution in Mie code. The effective variance, $v_{\text {eff }}$, is set to 0.088 . The real part of the refractive index is fixed to 1.337 , while the imaginary part, $k$, was set to 0 (blue) and to $0.0001 i$ (red).

ponent retrieved by POLDER (and consequently the AOT extrapolated at $532 \mathrm{~nm}$ ) cannot be accurately retrieved for

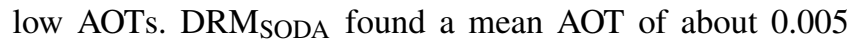
at $532 \mathrm{~nm}$ for the undetermined cases (see Fig. 6c). The result is likely due to the re-calibration process since DRM $\mathrm{Hu}$ found a background even larger than that of POLDER: about 0.12 at $532 \mathrm{~nm}$. It is difficult to assess the truthfulness of this background, considering the given level of accuracy of the POLDER method and the uncertainties associated with the lidar calibration. We assume that these background values are not physical and could be due to some inherent limitations of the retrieval methods. From our data, however, we cannot exclude the possibility that there is always a background loading of particles above clouds (e.g. aerosols or fine droplets in formation). Nevertheless, the main result of our investigation is that POLDER and DRM methods compare well for most situations with a mean difference of about \pm 0.07 in AOT at $532 \mathrm{~nm}$.

Although the number of cases is small, the results of the attached cases are interesting. They suggest that the lidar CALIOP and POLDER could be affected by layers of aerosols that physically and locally interact with the upper part of the cloud. In order to understand how the vertical profiles differ from one situation to another, we compared the CALIOP attenuated backscatter coefficient for attached and detached cases. We considered the period 2006-2010 and used data acquired over the entire globe. We only select the attached and detached cases where the cloud top altitude is below $1.5 \mathrm{~km}$, the COT is larger than 5 and the $\mathrm{DRM}_{\text {SODA }} \mathrm{AOT}_{532 \mathrm{~nm}}$ is larger than 0.1. These criteria allow for selection of data that correspond to AAC events associated with similar cloud vertical extents and with significant AOTs. For these cases, we computed the average and median of the CALIOP level 1 attenuated backscatter coefficients at $532 \mathrm{~nm}$. Figure 10 presents these results and some information concerning the mean and median values of CALIOP level 2 products: cloud top altitude, aerosol layer's base and top altitudes. The mean and median values computed for the AOTs retrieved by POLDER and DRM SODA $_{3}$ and the numbers of sampled events are also reported. Two different types of profiles can be observed for the detached and attached situations. For the detached cases, the aerosol and cloud backscattering profiles can be easily distinguished in both the median and mean profiles. The strong peaks in the backscatter profiles at around $1 \mathrm{~km}$ correspond to the top of the clouds, whereas the increase in the lidar backscatter signal observed between 2 and $4 \mathrm{~km}$ in altitude comes from the aerosols. For the attached situations, the backscatter profiles are noisier, which is likely due to the fact that the number of detected events is smaller compared to detached cases. The top of the cloud layer is still clearly visible in the mean and median backscattered lidar signals, but two maxima can be observed. We assume that we sampled two different regimes of clouds. In addition, there is a continuous transition in the backscatter signal between the top of the cloud and the above molecular atmosphere that is most clearly visible in the median profiles. This signal does not appear for the detached cases. This signal could explain the non-negligible above-

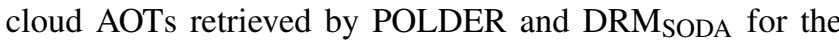
attached cases (see Fig. 5). It is difficult to assess the origin of the signal. It might be due to aerosols layers that penetrate the cloud layers at the top of the clouds. Natural aerosol or fine droplets in formation, commonly present in the vicinity of the clouds, might also create this additional signal.

Another hypothesis that could explain the low AOT correlation for the attached cases is that the aerosols located within the cloud layer could affect the polarized radiances measured by POLDER. Note that the polarized radiance at $865 \mathrm{~nm}$ is not affected by the vertical position of the aerosol layer as long as there is no contact between the aerosol and the cloud. Since the operational algorithm developed for POLDER assumes that the entire aerosol layer is located above the clouds, an additional polarized signal coming from aerosol located within the cloud would lead to an overestimation of the above-cloud AOT retrieved from POLDER. To test this assumption, we modelled the polarized radiance measured by POLDER for AAC scenes, considering different vertical locations of the aerosol layer (Fig. 11). We used the SOS radiative transfer code (Lenoble et al., 2007) for this simulation. We considered a liquid water cloud located between 0 and $1 \mathrm{~km}$. The particles (aerosol and cloud) are vertically homogeneously mixed. The COT is equal to 10 and the effective radius and variance are equal to $10 \mu \mathrm{m}$ and 0.08 , 

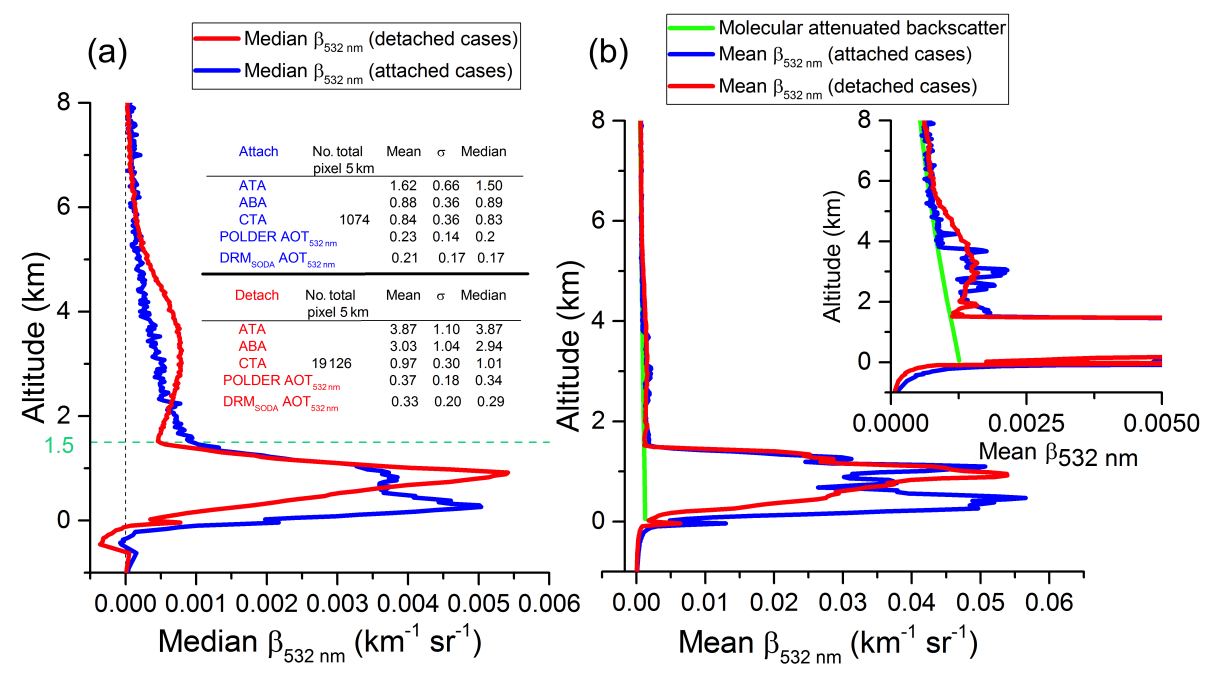

Figure 10. Median (a) and averaged (b) backscatter profiles $\left(\mathrm{km}^{-1} \mathrm{sr}^{-1}\right)$ for aerosol layer detached from the cloud layer (red) and aerosols attached to the top of the cloud (blue), for a period of 4.5 years on the global scale. For comparison, the molecular attenuated backscatter profile is shown as a green line. The data were filtered for a cloud top altitude lower than $1.5 \mathrm{~km}$, a cloud optical thickness (COT) larger than 5 and for a DRM SODA AOT at $532 \mathrm{~nm}$ larger than 0.1 . The number of $5 \mathrm{~km}$ horizontal-resolution pixels is also shown. The mean, standard deviation $(\sigma)$ and median of aerosol top altitude (ATA), aerosol base altitude (ABA) and cloud top altitude (CTA) are given for each situation. Same values are shown for POLDER AOT at and DRM SODA AOT at $532 \mathrm{~nm}$.

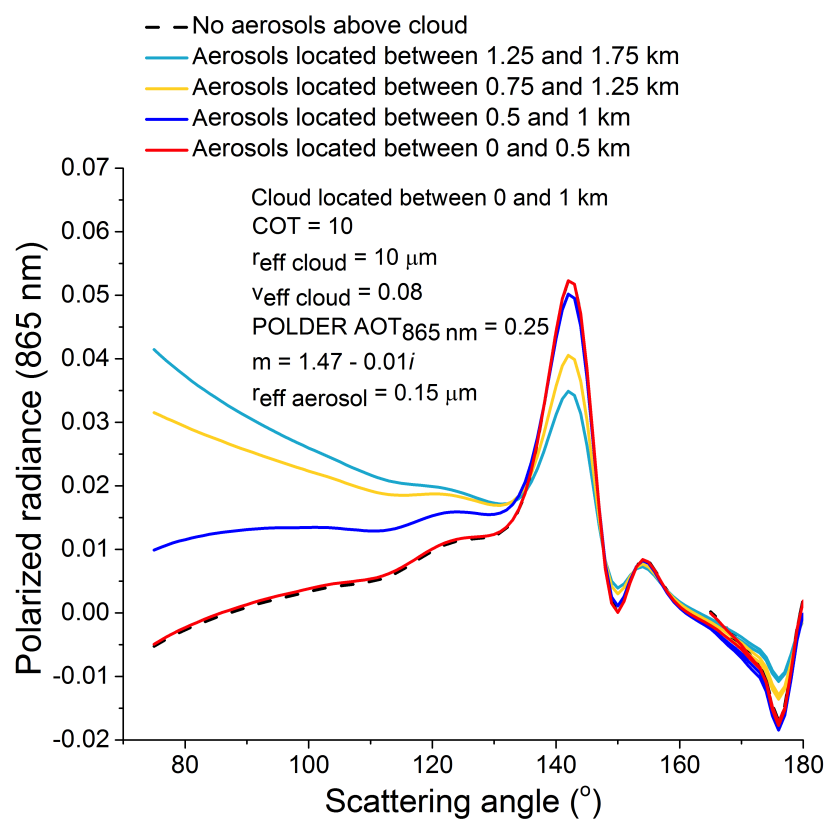

Figure 11. Sensitivity study of polarized radiance at $865 \mathrm{~nm}$ to the relative position of the aerosol layer above the cloud. Simulation performed for a cloud layer located between 0 and $1 \mathrm{~km}$ and aerosol layers varying at different altitudes. The cloud droplet effective radius is fixed to $10 \mu \mathrm{m}$ and the effective variance is 0.08 . The aerosol layer is characterized by an AOT of 0.25 at $865 \mathrm{~nm}$, a refractive index of $1.47-0.01 i$ and an aerosol effective radius of $0.15 \mu \mathrm{m}$. respectively. The aerosol layer is characterized by an AOT of 0.25 at $865 \mathrm{~nm}$, a refractive index of $m=1.47-0.01 i$ and an effective radius of $0.15 \mu \mathrm{m}$. Figure 11 shows the typical polarized feature for AAC events in case of detached situations (i.e. aerosols located between 1.25 and $1.75 \mathrm{~km}$ ): a creation of polarization is observed at side and forward scattering angles, whereas the cloud bow magnitude decreases. For the attached case (aerosols between 0.75 and $1.25 \mathrm{~km}$ ), the amount of polarization created at forward scattering angles decreases and the cloud bow attenuation is less significant in comparison with the detached scenario. When the aerosol layer is located within the upper part of the cloud layer (between 0.5 and $1 \mathrm{~km}$ ) we still observe a weak polarized signal created at forward scattering angles. When the aerosol layer is located in the lower part of the cloud layer, the effects of the aerosols disappear since the polarized radiance scattered by the aerosols is lost due to multiple scattering occurring within the clouds. These simulations were processed with the POLDER algorithm (Waquet et al., 2013b). We recall that the LUTs used in this algorithm were built for detached situations. The algorithm retrieved an AOT of 0.09 at $865 \mathrm{~nm}$ when the aerosols are located within the upper part of the cloud layer. This demonstrates that polarized radiances are sensitive to aerosols situated within the clouds for the attached cases.

The DRM methods might also be impacted by the presence of aerosols within the clouds. Aerosols as a solution within the cloud droplets (i.e. internal mixture) might impact the chemical composition of the droplets and modify their ability to backscatter light. Figure 9 shows lidar ratio 
computed for absorbing cloud droplets. We used an imaginary part of 0.0001 for the complex refractive index of the droplets. This might simulate, for instance, the properties of brown clouds contaminated by absorbing aerosols. The chosen value is in agreement with the refractive indices given for water containing soot inclusions with volume fractions ranging between $10^{-4}$ and $10^{-2}$ (Erlick, 2006). We observe a drastic increase of $S_{\mathrm{c}}$ with $r_{\text {eff }}$ (from $21.7 \mathrm{sr}$ at $5 \mu \mathrm{m}$ to $50 \mathrm{sr}$ at $40 \mu \mathrm{m}$ ) when the water droplet is weakly absorbing. In the case of an external mixture, we assume that the presence of aerosols at the top of cloud might also modify the value of $S_{\mathrm{c}}$. Any deviation from the $19 \mathrm{sr}$ value assumed for the droplets lidar ratio in Eq. (9) will necessarily impact the retrieved AOT and the differences observed between the AOT estimates provided by the POLDER and DRM methods.

\section{Conclusions}

In this study, we compared and analysed the consistency of the AOT and AE retrievals above clouds from different passive and active techniques. We used the CALIOP operational algorithm (Winker et al., 2009), the POLDER polarization method (Waquet et al., 2013b) and the CALIOP-based depolarization ratio method $\left(\mathrm{DRM}_{\mathrm{Hu}}\right)$ (Hu et al., 2007a), for which we proposed a re-calibrated version of the DRM

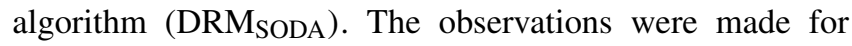
(a) three case studies corresponding to an African biomassburning event, a Saharan dust event and a Siberian biomassburning event; (b) a regional-scale analysis over South Atlantic Ocean, North Atlantic Ocean and North Pacific Ocean for a period of 6 months in 2008; and (c) a global-scale analysis for different vertical layer distributions for the period 2006-2010.

In the regional analysis, we observed that POLDER method and DRM are in good agreement when the microphysics of aerosols is dominated by fine-mode particles of biomass-burning aerosols (in the South Atlantic region, $R^{2}=0.83$ ) or coarse-mode aerosols of dust (in the North Atlantic region, $\left.R^{2}=0.82\right)$. A good correlation between these methods ( $R^{2}=0.68$ ) is also noticed in the global treatment, when the aerosol and cloud layers are well separated. Nevertheless, some of the detached cases considered in our study, mainly the ones associated with optically thick smoke layers, are likely to be incorrectly classified as detached. As a future perspective, these misclassified detached cases (due to strong attenuation of the CALIOP $532 \mathrm{~nm}$ signal) could be detected by controlling the CALIOP $1064 \mathrm{~nm}$ signal, which was shown to provide more sensitivity to the entire vertical extent of these absorbing aerosol layers. The CALIOP operational method largely underestimates the AOT above clouds in all situations, with respect to other methods.

The differences between the DRM and POLDER retrievals increase when a complex mixture of aerosols is expected (such as in the East Asia region). This is probably due to the fact that the current algorithm developed for POLDER uses a limited number of microphysical models of aerosols. Also, the relative position of the aerosol layer above the cloud impacts the AOT retrievals from both active and passive measurements: the correlation decreases when the layers are in contact $\left(R^{2}=0.36\right)$, suggesting that aerosols at the top or within the cloud can affect the AOT retrievals. One hypothesis is that an additional polarized signal coming from aerosol located within the cloud could affect the polarization signal and method, which leads to an overestimation of the AOT retrieved with POLDER algorithm. The aerosols attached with or within the cloud also have the potential to impact the DRM retrievals by modifying the lidar ratio (and consequently the AOT) as a result of internal or external mixture.

Furthermore, we investigated potential biases in the re-

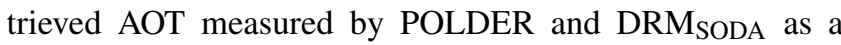
function of MODIS cloud properties (i.e. droplet effective radius $\left(r_{\text {eff }}\right)$ and COT). The tendencies show an increase in the difference between the two methods for larger $r_{\mathrm{eff}}$, suggesting sensitivity to the cloud droplet effective radius. For this reason, we recalculated the $\mathrm{DRM}_{\mathrm{SODA}} \mathrm{AOT}_{532 \mathrm{~nm}}$, taking into account the dependence of lidar ratio on $r_{\text {eff }}$, as this method assumes a constant lidar ratio regarding the droplet effective radius. By doing so, we observed a decrease in the difference between POLDER and DRM methods and a shift of the DRM AOT values from negative to positive. For a better accuracy of DRM retrievals in future studies, this correction should be taken into account. The results show also that the multiple scattering processes, which are more pronounced in optically thick clouds, could also affect the DRM technique.

All of the aforementioned situations have revealed that DRM $_{\mathrm{Hu}}$ has larger mean AOT than that of DRM $\mathrm{SODA}$. This is likely to be a consequence of the re-calibration performed for

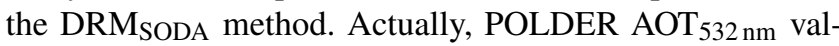
ues are consistently smaller than the ones of $\mathrm{DRM}_{\mathrm{Hu}}$ and

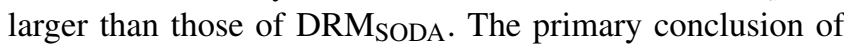
our investigation is that POLDER and DRM techniques are comparable for the majority of cases, with a mean difference of about \pm 0.07 in AOT at $532 \mathrm{~nm}$, depending on lidar calibration.

Given the fact that each method relies upon different physical concepts, applied to different sensors and measurements, the high value of the correlation obtained for the AOT retrievals is a remarkable result that highlights the coherence between active and passive methods for aerosols above clouds. Nonetheless, more efforts have to be done to increase the accuracy of the methods in order to better understand aerosols above clouds and their related effects. Airborne measurements are extremely useful in providing information on aerosols' above-cloud properties. Several ongoing and planned airborne field campaigns will attempt to characterize the properties of biomass-burning aerosols over the South Atlantic Ocean (Zuidema et al., 2016). Planned measurements from the French Falcon 20 aircraft, equipped 
with a high-resolution lidar, an airborne sun photometer and a POLDER-like sensor, will notably be considered for a future validation of CALIOP DRM and POLDER abovecloud aerosol products. Another perspective is to improve the POLDER algorithm by introducing additional dust or mixture models with larger or smaller effective radii values in the LUT. This would definitely improve the AOT and AE retrievals in more complex situations (such as East Asia region). Also, our results suggest that a combination of POLDER and DRM methods has the potential to detect aerosols within clouds. It is very relevant to study these situations, since they can affect the retrievals and provide important information regarding the cloud processes. A further perspective would be to exploit the synergy between CALIOP and POLDER to infer the direct aerosol radiative forcing, aerosol heating rates and the semi-direct effect of absorbing aerosols located above clouds.

Data availability. All data are available at ICARE website on-line archive: http://www.icare.univ-lille1.fr/archive.

Competing interests. The authors declare that they have no conflict of interest.

Acknowledgements. Lucia Deaconu's grant is provided by the CaPPA project (Chemical and Physical Properties of the Atmosphere), which is funded by the French National Research Agency (ANR) through the PIA (Programme d'Investissement d'Avenir) under contract ANR-11-LABX-0005-01 and by the Regional Council Hauts-de-France and the European Funds for Regional Economic Development (FEDER).

Edited by: Piet Stammes

Reviewed by: Hiren Jethva and two anonymous referees

\section{References}

Balkanski, Y., Schulz, M., Claquin, T., and Guibert, S.: Reevaluation of Mineral aerosol radiative forcings suggests a better agreement with satellite and AERONET data, Atmos. Chem. Phys., 7, 81-95, https://doi.org/10.5194/acp-7-81-2007, 2007.

Bates, D. R.: Rayleigh scattering by air, Planet. Space Sci., 32, 785790, 1984.

Cao, X., Roy, G., Roy, N., and Bernier, R.: Comparison of the relationships between lidar integrated backscattered light and accumulated depolarization ratios for linear and circular polarization for water droplets, fog oil, and dust, Appl. Opt., 48, 4130-4141, https://doi.org/10.1364/AO.48.004130, 2009.

Cattrall, C., Reagan, J., Thome, K., and Dubovik, O.: Variability of aerosol and spectral lidar and backscatter and extinction ratios of key aerosol types derived from selected Aerosol Robotic Network locations, J. Geophys. Res., 110, D10S11, https://doi.org/10.1029/2004JD005124, 2005.
Chand, D., Anderson, T. L., Wood, R., Charlson, R. J., Hu, Y., Liu, Z., and Vaughan, M.: Quantifying above-cloud aerosol using spaceborne lidar for improved understanding of cloudysky direct climate forcing, J. Geophys. Res., 113, D13206, https://doi.org/10.1029/2007JD009433, 2008.

Chand, D., Wood, R., Anderson, T. L., Satheesh, S. K., and Charlson, R. J.: Satellite-derived direct radiative effect of aerosols dependent on cloud cover, Nat. Geosci., 2, 181-184, https://doi.org/10.1038/ngeo437, 2009.

Costantino, L. and Bréon, F.-M.: Aerosol indirect effect on warm clouds over South-East Atlantic, from co-located MODIS and CALIPSO observations, Atmos. Chem. Phys., 13, 69-88, https://doi.org/10.5194/acp-13-69-2013, 2013.

Deuzé, J. L., Herman, M., and Santer, R.: Fourier series expansion of the transfer equation in the atmosphereocean system, J. Quant. Spectrosc. Ra., 41, 483-494, https://doi.org/10.1016/0022-4073(89)90118-0, 1989.

Dubovik, O., Holben, B., Eck, T. F., Smirnov, A., Kaufman, Y. J., King, M. D., Tanré, D., and Slutsker, I.: Variability of Absorption and Optical Properties of Key Aerosol Types Observed in Worldwide Locations, J. Atmos. Sci., 59, 590-608, https://doi.org/10.1175/15200469(2002)059<0590:VOAAOP>2.0.CO;2, 2002.

Erlick, C.: Effective Refractive Indices of Water and Sulfate Drops Containing Absorbing Inclusions, J. Atmos. Sci., 63, 754-763, https://doi.org/10.1175/JAS3635.1, 2006.

Feng, N. and Christopher, S. A.: Measurement-based estimates of direct radiative effects of absorbing aerosols above clouds, J. Geophys. Res.-Atmos., 120, 6908-6921, https://doi.org/10.1002/2015JD023252, 2015.

De Graaf, M., Bellouin, N., Tilstra, L. G., Haywood, J., and Stammes, P.: Aerosol direct radiative effect of smoke over clouds over the southeast Atlantic Ocean from 2006 to 2009, Geophys. Res. Lett., 41, 7723-7730, https://doi.org/10.1002/2014GL061103, 2014.

Hansen, J., Sato, M., and Ruedy, R.: Radiative forcing and climate response, J. Geophys. Res.-Atmos., 102, 6831-6864, https://doi.org/10.1029/96JD03436, 1997.

Hasekamp, O. P.: Capability of multi-viewing-angle photopolarimetric measurements for the simultaneous retrieval of aerosol and cloud properties, Atmos. Meas. Tech., 3, 839-851, https://doi.org/10.5194/amt-3-839-2010, 2010.

Haywood, J. M., Osborne, S. R., and Abel, S. J.: The effect of overlying absorbing aerosol layers on remote sensing retrievals of cloud effective radius and cloud optical depth, Q. J. Roy. Meteor. Soc., 130, 779-800, https://doi.org/10.1256/qj.03.100, 2004.

Herman, M., Deuzé, J. L., Marchand, A., Roger, B., and Lallart, P.: Aerosol remote sensing from POLDER/ADEOS over the ocean: Improved retrieval using a nonspherical particle model, J. Geophys. Res.-Atmos., 110, 1-11, https://doi.org/10.1029/2004JD004798, 2005.

Hu, Y.: Depolarization ratio-effective lidar ratio relation: Theoretical basis for space lidar cloud phase discrimination, Geophys. Res. Lett., 34, L11812, https://doi.org/10.1029/2007GL029584, 2007.

Hu, Y., Liu, Z., Winker, D., Vaughan, M., Noel, V., Bissonnette, L., Roy, G., and McGill, M.: Simple relation between lidar multiple scattering and depolarization for water clouds, Opt. Lett., 31, 1809, https://doi.org/10.1364/OL.31.001809, 2006. 
Hu, Y., Vaughan, M., Liu, Z., Powell, K., and Rodier, S.: Retrieving Optical Depths and Lidar Ratios for Transparent Layers Above Opaque Water Clouds From CALIPSO Lidar Measurements, IEEE Geosci. Remote Sens., 4, 523-526, https://doi.org/10.1109/LGRS.2007.901085, 2007a.

Hu, Y., Vaughan, M., Liu, Z., Lin, B., Yang, P., Flittner, D., Hunt, B., Kuehn, R., Huang, J., Wu, D., Rodier, S., Powell, K., Trepte, C., and Winker, D.: The depolarization - attenuated backscatter relation: CALIPSO lidar measurements vs. theory, Opt. Express, 15, 5327-5332, https://doi.org/10.1364/OE.15.005327, 2007b.

Hunt, W. H., Winker, D. M., Vaughan, M. A., Powell, K. A., Lucker, P. L., Weimer, C., Hunt, W. H., Winker, D. M., Vaughan, M. A., Powell, K. A., Lucker, P. L., and Weimer, C.: CALIPSO Lidar Description and Performance Assessment, J. Atmos. Ocean. Tech., 26, 1214-1228, https://doi.org/10.1175/2009JTECHA1223.1, 2009.

IPCC: Climate Change 2013: The Physical Science Basis, Contribution of Working Group I to the Fifth Assessment Report of the Intergovernmental Panel on Climate Change, edited by: Stocker, T. F., Qin, D., Plattner, G.-K., Tignor, M., Allen, S. K., Boschung, J., Nauels, A., Xia, Y., Bex, V., and Midgley, P. M., Cambridge University Press, Cambridge, UK, New York, NY, USA, 1535 pp., https://doi.org/10.1017/CBO9781107415324, 2013.

Jethva, H., Torres, O., Remer, L. A., and Bhartia, P. K.: A color ratio method for simultaneous retrieval of aerosol and cloud optical thickness of above-cloud absorbing aerosols from passive sensors: Application to MODIS measurements, IEEE T. Geosci. Remote, 51, 3862-3870, https://doi.org/10.1109/TGRS.2012.2230008, 2013

Jethva, H., Torres, O., Waquet, F., Chand, D., and Hu, Y.: How do A-train sensors intercompare in the retrieval of above-cloud aerosol optical depth? A case study-based assessment, Geophys. Res. Lett., 41, 186-192, https://doi.org/10.1002/2013GL058405, 2014.

Johnson, B. T., Shine, K. P., and Forster, P. M.: The semidirect aerosol effect: Impact of absorbing aerosols on marine stratocumulus, Q. J. Roy. Meteor. Soc., 130, 1407-1422, https://doi.org/10.1256/qj.03.61, 2004.

Josset, D., Hu, Y., Pelon, J., Zhai, P., Tanré, D., Rogers, R., Lucker, P., Trepte, C., Powell, K., Rodier, S., Pascal, N., and Team, T. I.: Advances in Research Products From CALIPSO: Optical Depth Direct Retrieval Over Ocean, Water Clouds and Land, 25th International Laser Radar Conference (ILRC), Curran Associates, Inc., Curran Associates, Inc., 1280-1283, 2010.

Josset, D., Rogers, R., Pelon, J., Hu, Y., Liu, Z., Omar, A., Zhai, P.-W., Fernald, F. G., Herman, B. M., Reagan, J. A., Winker, D. M., Pelon, J., Coakley, J. A., Ackerman, S. A., Charlson, R. J., Colarco, P. R., Flamant, P., Fu, Q., Hoff, R., Kittaka, C., Kubar, T. L., LeTreut, H., McCormick, M. P., Megie, G., Poole, L., Powell, K., Trepte, C., Vaughan, M. A., Wielicki, B. A., Stephens, G. L., Vane, D. G., Tanelli, S., Im, E., Durden, S., Rokey, M., Reinke, D., Partain, P., Mace, G. G., Austin, R., Haynes, J., Lebsock, M., Suzuki, K., Waliser, D., Wu, D., Kay, J., Gettelman, A., Wang, Z., and Marchand, R.: CALIPSO lidar ratio retrieval over the ocean, Opt. Express, 19, 18696-18706, https://doi.org/10.1364/OE.19.018696, 2011.

Josset, D., Pelon, J., Hu, Y., Rogers, R., Liu, Z., Omar, A., Vaughan, M., Zhai, P., and Team, I.: Global scale lidar ratio retrieval over the ocean, 26th International Laser Radar Conference (ILRC 26), Porto Heli, Greece, 25-29 June, 2012.

Kaufman, Y. J., Tanré, D., and Boucher, O.: A satellite view of aerosols in the climate system, Nature, 419, 215-23, https://doi.org/10.1038/nature01091, 2002.

Keil, A. and Haywood, J. M.: Solar radiative forcing by biomass burning aerosol particles during SAFARI 2000: A case study based on measured aerosol and cloud properties, J. Geophys. Res.-Atmos., 108, 8467, https://doi.org/10.1029/2002JD002315, 2003.

King, L. V: On the Complex Anisotropic Molecule in Relation to the Dispersion and Scattering of Light, P. Roy. Soc. A-Math. Phy., 104, 333-357, 1923.

Knobelspiesse, K., Cairns, B., Ottaviani, M., Ferrare, R., Hair, J., Hostetler, C., Obland, M., Rogers, R., Redemann, J., Shinozuka, Y., Clarke, A., Freitag, S., Howell, S., Kapustin, V., and McNaughton, C.: Combined retrievals of boreal forest fire aerosol properties with a polarimeter and lidar, Atmos. Chem. Phys., 11, 7045-7067, https://doi.org/10.5194/acp-11-7045-2011, 2011.

Lenoble, J., Herman, M., Deuzé, J. L., Lafrance, B., Santer, R., and Tanré, D.: A successive order of scattering code for solving the vector equation of transfer in the earth's atmosphere with aerosols, J. Quant. Spectrosc. Ra., 107, 479-507, https://doi.org/10.1016/j.jqsrt.2007.03.010, 2007.

Meyer, K., Platnick, S., Oreopoulos, L., and Lee, D.: Estimating the direct radiative effect of absorbing aerosols overlying marine boundary layer clouds in the southeast Atlantic using MODIS and CALIOP, J. Geophys. Res.-Atmos., 118, 48014815, https://doi.org/10.1002/jgrd.50449, 2013.

Meyer, K., Platnick, S., and Zhang, Z.: Simultaneously inferring above-cloud absorbing aerosol optical thickness and underlying liquid phase cloud optical and microphysical properties using MODIS, J. Geophys. Res.-Atmos., 120, 5524-5547, https://doi.org/10.1002/2015JD023128, 2015.

Miles, N. L., Verlinde, J., Clothiaux, E. E., Miles, N. L., Verlinde, J., and Clothiaux, E. E.: Cloud Droplet Size Distributions in Low-Level Stratiform Clouds, J. Atmos. Sci., 57, 295-311, https://doi.org/10.1175/15200469(2000)057<0295:CDSDIL>2.0.CO;2, 2000.

Myhre, G., Shindell, D., Bréon, F.-M., Collins, W., Fuglestvedt, J., Huang, J., Koch, D., Lamarque, J.-F., Lee, D., Mendoza, B., Nakajima, T., Robock, A., Stephens, G., Takemura, T., and Zhang, H.: Anthropogenic and Natural Radiative Forcing, Intergovernmental Panel on Climate Change (IPCC), Cambridge University Press, 659-740, https://doi.org/10.1017/CBO9781107415324.018, 2013a.

Myhre, G., Samset, B. H., Schulz, M., Balkanski, Y., Bauer, S., Berntsen, T. K., Bian, H., Bellouin, N., Chin, M., Diehl, T., Easter, R. C., Feichter, J., Ghan, S. J., Hauglustaine, D., Iversen, T., Kinne, S., Kirkevåg, A., Lamarque, J.-F., Lin, G., Liu, X., Lund, M. T., Luo, G., Ma, X., van Noije, T., Penner, J. E., Rasch, P. J., Ruiz, A., Seland, Ø., Skeie, R. B., Stier, P., Takemura, T., Tsigaridis, K., Wang, P., Wang, Z., Xu, L., Yu, H., Yu, F., Yoon, J.-H., Zhang, K., Zhang, H., and Zhou, C.: Radiative forcing of the direct aerosol effect from AeroCom Phase II simulations, Atmos. Chem. Phys., 13, 1853-1877, https://doi.org/10.5194/acp13-1853-2013, $2013 b$.

O'Connor, E. J., Illingworth, A. J., and Hogan, R. J.: A Technique for Autocalibration of Cloud Lidar, J. At- 
mos. Ocean. Tech., 21, 777-786, https://doi.org/10.1175/15200426(2004)021<0777:ATFAOC>2.0.CO;2, 2004.

Omar, A. H., Won, J.-G., Winker, D. M., Yoon, S.-C., Dubovik, O., and Mccormick, M. P.: Development of global aerosol models using cluster analysis of Aerosol Robotic Network (AERONET) measurements, J. Geophys. Res, 110, 10-14, https://doi.org/10.1029/2004JD004874, 2005.

Omar, A. H., Winker, D. M., Vaughan, M. A., Hu, Y., Trepte, C. R., Ferrare, R. A., Lee, K.-P., Hostetler, C. A., Kittaka, C., Rogers, R. R., Kuehn, R. E., Liu, Z., Omar, A. H., Winker, D. M., Vaughan, M. A., Hu, Y., Trepte, C. R., Ferrare, R. A., Lee, K.-P., Hostetler, C. A., Kittaka, C., Rogers, R. R., Kuehn, R. E., and Liu, Z.: The CALIPSO Automated Aerosol Classification and Lidar Ratio Selection Algorithm, J. Atmos. Ocean. Tech., 26, 1994-2014, https://doi.org/10.1175/2009JTECHA1231.1, 2009.

Peers, F., Waquet, F., Cornet, C., Dubuisson, P., Ducos, F., Goloub, P., Szczap, F., Tanré, D., and Thieuleux, F.: Absorption of aerosols above clouds from POLDER/PARASOL measurements and estimation of their direct radiative effect, Atmos. Chem. Phys., 15, 4179-4196, https://doi.org/10.5194/acp15-4179-2015, 2015.

Peers, F., Bellouin, N., Waquet, F., Ducos, F., Goloub, P., Mollard, J., Myhre, G., Skeie, R. B., Takemura, T., Tanré, D., Thieuleux, F., and Zhang, K.: Comparison of aerosol optical properties above clouds between POLDER and AeroCom models over the South East Atlantic Ocean during the fire season, Geophys. Res. Lett., 43, 3991-4000, https://doi.org/10.1002/2016GL068222, 2016.

Pinnick, R. G., Jennings, S. G., Chýlek, P., Ham, C., and Grandy, W. T.: Backscatter and extinction in water clouds, J. Geophys. Res., 88, 6787, https://doi.org/10.1029/JC088iC11p06787, 1983.

Platt, C. M. R.: Remote Sounding of High Clouds: I. Calculation of Visible and Infrared Optical Properties from Lidar and Radiometer Measurements, J. Appl. Meteorol., 18, 1130-1143, https://doi.org/10.1175/15200450(1979)018<1130:RSOHCI>2.0.CO;2, 1979.

Powell, K., Vaughan, M., Winker, D., Lee, K. P., Pitts, M., Trepte, C., Detweiler, P., Hunt, W., Lambeth, J., and Lucker, P.: Cloud-Aerosol LIDAR Infrared Pathfinder Satellite Observations (CALIPSO), Data Manag. Syst. Data, Prod. Cat. Doc. No. PC-SCI-503, Release, 3, 2010.

Ramanathan, V., Crutzen, P. J., Kiehl, J. T., and Rosenfeld, D.: Aerosols, climate, and the hydrological cycle., Science, 294, 2119-2124, https://doi.org/10.1126/science.1064034, 2001.

Riedi, J., Marchant, B., Platnick, S., Baum, B. A., Thieuleux, F., Oudard, C., Parol, F., Nicolas, J.-M., and Dubuisson, P.: Cloud thermodynamic phase inferred from merged POLDER and MODIS data, Atmos. Chem. Phys., 10, 11851-11865, https://doi.org/10.5194/acp-10-11851-2010, 2010.

Rosenfeld, D.: Suppression of Rain and Snow by Urban and Industrial Air Pollution, Science, 287, 1793-1796, https://doi.org/10.1126/science.287.5459.1793, 2000.

Sassen, K.: The Polarization Lidar Technique for Cloud Research: A Review and Current Assessment, B. Am. Meteorol. Soc., 72, 1848-1866, https://doi.org/10.1175/15200477(1991)072<1848:TPLTFC>2.0.CO;2, 1991.

Sassen, K. and Zhu, J.: A global survey of CALIPSO linear depolarization ratios in ice clouds: Initial findings, J. Geophys. Res.-
Atmos., 114, D00H07, https://doi.org/10.1029/2009JD012279, 2009.

Tanré, D., Bréon, F. M., Deuzé, J. L., Dubovik, O., Ducos, F., François, P., Goloub, P., Herman, M., Lifermann, A., and Waquet, F.: Remote sensing of aerosols by using polarized, directional and spectral measurements within the A-Train: the PARASOL mission, Atmos. Meas. Tech., 4, 1383-1395, https://doi.org/10.5194/amt-4-1383-2011, 2011.

Torres, O., Jethva, H., and Bhartia, P. K.: Retrieval of Aerosol Optical Depth above Clouds from OMI Observations: Sensitivity Analysis and Case Studies, J. Atmos. Sci., 69, 1037-1053, https://doi.org/10.1175/JAS-D-11-0130.1, 2012.

Torres, O., Ahn, C., and Chen, Z.: Improvements to the OMI near-UV aerosol algorithm using A-train CALIOP and AIRS observations, Atmos. Meas. Tech., 6, 3257-3270, https://doi.org/10.5194/amt-6-3257-2013, 2013.

Twomey, S.: Pollution and the planetary albedo, Atmos. Environ., 8, 1251-1256, https://doi.org/10.1016/0004-6981(74)90004-3, 1974.

Vaughan, M. A., Powell, K. A., Winker, D. M., Hostetler, C. A., Kuehn, R. E., Hunt, W. H., Getzewich, B. J., Young, S. A., Liu, Z., and McGill, M. J.: Fully Automated Detection of Cloud and Aerosol Layers in the CALIPSO Lidar Measurements, J. Atmos. Ocean. Tech., 26, 2034-2050, https://doi.org/10.1175/2009JTECHA1228.1, 2009.

Waquet, F., Riedi, J., Labonnote, L. C., Goloub, P., Cairns, B., Deuzé, J.-L., and Tanré, D.: Aerosol Remote Sensing over Clouds Using A-Train Observations, J. Atmos. Sci., 66, 24682480, https://doi.org/10.1175/2009JAS3026.1, 2009.

Waquet, F., Peers, F., Ducos, F., Goloub, P., Platnick, S., Riedi, J., Tanré, D., and Thieuleux, F.: Global analysis of aerosol properties above clouds, Geophys. Res. Lett., 40, 5809-5814, https://doi.org/10.1002/2013GL057482, 2013a.

Waquet, F., Cornet, C., Deuzé, J.-L., Dubovik, O., Ducos, F., Goloub, P., Herman, M., Lapyonok, T., Labonnote, L. C., Riedi, J., Tanré, D., Thieuleux, F., and Vanbauce, C.: Retrieval of aerosol microphysical and optical properties above liquid clouds from POLDER/PARASOL polarization measurements, Atmos. Meas. Tech., 6, 991-1016, https://doi.org/10.5194/amt-6-9912013, 2013b.

Waquet, F., Péré, J.-C., Peers, F., Goloub, P., Ducos, F., Thieuleux, F., and Tanré, D.: Global detection of absorbing aerosols over the ocean in the red and near-infrared spectral region, J. Geophys. Res.-Atmos., 121, 10902-10918, https://doi.org/10.1002/2016JD025163, 2016.

Warren, S. G., Hahn, C. J., London, J., Chervin, R. M., and Jenne, R. L.: Global Distribution of Total Cloud Cover and Cloud Amounts over the Ocear, NCAR Tech. Note, NCAR/TN-27, https://doi.org/10.2172/5415329, 1988.

Wilcox, E. M.: Stratocumulus cloud thickening beneath layers of absorbing smoke aerosol, Atmos. Chem. Phys., 10, 1176911777, https://doi.org/10.5194/acp-10-11769-2010, 2010.

Winker, D. M., Hunt, W. H., and McGill, M. J.: Initial performance assessment of CALIOP, Geophys. Res. Lett., 34, L19803, https://doi.org/10.1029/2007GL030135, 2007.

Winker, D. M., Vaughan, M. A., Omar, A., Hu, Y., Powell, K. A., Liu, Z., Hunt, W. H., and Young, S. A.: Overview of the CALIPSO Mission and CALIOP Data Pro- 
cessing Algorithms, J. Atmos. Ocean. Tech., 26, 2310-2323, https://doi.org/10.1175/2009JTECHA1281.1, 2009.

Winker, D. M., Pelon, J., Jr., J. A. C., Ackerman, S. A., Charlson, R. J., Colarco, P. R., Flamant, P., Fu, Q., Hoff, R. M., Kittaka, C., Kubar, T. L., Treut, H. Le, McCormick, M. P., Mégie, G., Poole, L., Powell, K., Trepte, C., Vaughan, M. A. and Wielicki, B. A.: The CALIPSO Mission: A Global 3D View of Aerosols and Clouds, B. Am. Meteorol. Soc., 91, 1211-1229, https://doi.org/10.1175/2010BAMS3009.1, 2010.

$\mathrm{Xu}, \mathrm{M}$. and Alfano, R. R.: Random Walk of Polarized Light in Turbid Media, Phys. Rev. Lett., 95, 213901, https://doi.org/10.1103/PhysRevLett.95.213901, 2005.

Young, S. A. and Vaughan, M. A.: The Retrieval of Profiles of Particulate Extinction from Cloud-Aerosol Lidar Infrared Pathfinder Satellite Observations (CALIPSO) Data: Algorithm Description, J. Atmos. Ocean. Tech., 26, 1105-1119, https://doi.org/10.1175/2008JTECHA1221.1, 2009.

Yu, H., Kaufman, Y. J., Chin, M., Feingold, G., Remer, L. A., Anderson, T. L., Balkanski, Y., Bellouin, N., Boucher, O., Christopher, S., DeCola, P., Kahn, R., Koch, D., Loeb, N., Reddy, M. S., Schulz, M., Takemura, T., and Zhou, M.: A review of measurement-based assessments of the aerosol direct radiative effect and forcing, Atmos. Chem. Phys., 6, 613-666, https://doi.org/10.5194/acp-6-613-2006, 2006.

Yu, H., Remer, L. A., Chin, M., Bian, H., Kleidman, R. G., and Diehl, T.: A satellite-based assessment of transpacific transport of pollution aerosol, J. Geophys. Res., 113, D14S12, https://doi.org/10.1029/2007JD009349, 2008.
Zhang, Y. H., Wooster, M. J., Tutubalina, O., and Perry, G. L. W.: Monthly burned area and forest fire carbon emission estimates for the Russian Federation from SPOT VGT, Remote Sens. Environ., 87, 1-15, https://doi.org/10.1016/S0034-4257(03)00141-X, 2003.

Zhang, Z., Meyer, K., Yu, H., Platnick, S., Colarco, P., Liu, Z., and Oreopoulos, L.: Shortwave direct radiative effects of above-cloud aerosols over global oceans derived from 8 years of CALIOP and MODIS observations, Atmos. Chem. Phys., 16, 2877-2900, https://doi.org/10.5194/acp-16-2877-2016, 2016.

Zuidema, P., Redemann, J., Haywood, J., Wood, R., Piketh, S., Hipondoka, M., Formenti, P., Zuidema, P., Redemann, J., Haywood, J., Wood, R., Piketh, S., Hipondoka, M., and Formenti, P.: Smoke and Clouds above the Southeast Atlantic: Upcoming Field Campaigns Probe Absorbing Aerosol's Impact on Climate, B. Am. Meteorol. Soc., 97, 1131-1135, https://doi.org/10.1175/BAMS-D-15-00082.1, 2016. 